Mindfulness, Connectedness to Nature, Personal Ecological Norm and Pro-environmental Behavior: A Daily Diary Study

\author{
Nadine Richter ${ }^{\text {a }}$ \& Marcel Hunecke ${ }^{\text {a }}$ \\ ${ }^{a}$ Faculty of Applied Social Sciences, University of Applied Sciences and Arts Dortmund
}

This uncorrected manuscript was accepted in January 2022 in Current Research in Ecological and Social Psychology (DOI: https://doi.org/10.1016/j.cresp.2022.100038 ). Please check the journal homepage for the final manuscript.

Version: 22.11.2021

Corresponding author: Nadine Richter, University of Applied Sciences and Arts Dortmund, Emil-Figge-

Straße 44, 44227 Dortmund, Germany, Email: nadine.richter@fh-dortmund.de 


\begin{abstract}
The mindfulness concept has been discussed as a promising pathway to increased proenvironmental behavior, that is at the same time related to personal well-being. A number of studies identified correlations between trait mindfulness and pro-environmental behavior (PEB) and identified different mediators. In order to gain more fine-grained insights into this connection, the present study investigated mindfulness as a predictor of same-day connectedness to nature, personal ecological norm activation (PENA), PEB and well-being on a within-person level. In a daily diary study $(N=183$, days $=$ 1197), multilevel regression analysis showed (i) positive same-day within-person relationships between mindfulness and PENA, connectedness to nature and well-being, (ii) a significant effect of mindfulness on next-days PEB, (iii) relationships between regular mind-body practices, such as mindfulness meditation, and daily PEB. Path analysis showed, (iv) a path from mindfulness to PEB mediated by connectedness to nature and PENA. The study confirms the significance of mindfulness in every-day life for connectedness to nature, PENA and well-being. Furthermore, the study points out to the relevance of investigating predictors of PEB on a within-person level.
\end{abstract}

Keywords: mindfulness, connectedness to nature, pro-environmental behavior, well-being, daily diary 


\section{Are Mindful Days More Sustainable? Mindfulness, Connectedness to Nature, Personal Norm and Pro-environmental Behavior in a Daily Diary Study}

The climate crisis calls for a shift in individual lifestyles through more pro-environmental behavior (PEB) decisions in every-day life. The mindfulness concept has been discussed as a promising pathway to PEB, because it is related with individual well-being at the same time (Ericson et al., 2014; Geiger et al., 2019; Hunecke, 2018; Kasser, 2017; Thiermann and Sheate, 2020b). Some studies have already confirmed a relationship between dispositional mindfulness and PEB (Geiger et al., 2019). In this context, connectedness to nature as well as personal ecological norm are two of the relevant mediators between mindfulness and PEB (Barbaro and Pickett, 2016; Richter and Hunecke, 2020). However, as most of the previous studies used cross-sectional between-person study designs, no insights as to daily variations and within-person relationships of mindfulness and PEB can be derived. In contrast to cross-sectional studies, the focus on within-person relationships over a course of days allows conclusions about intrapersonal connections between psychological constructs (Curran and Bauer, 2011). Therefore, the investigation of daily covariations of PEB and its psychological predictors can give insights into the everyday mechanisms of PEB decisions. Furthermore, the investigation of same-day and time-lagged relationships allows to obtain information regarding the temporal order of variables. In the present daily diary study, we tested within-person relationships between self-reported daily measures of mindfulness, connectedness to nature, personal ecological norm activation (PENA) and PEB. Mindfulness is not only conceptualized as a disposition but is also described as a form of practice. We therefore investigated mind-body practice (MBP), which includes mindfulness meditation and body-oriented forms of meditation (e.g. yoga), complementary to dispositional mindfulness. In this context, we focused on differences between mind-body practitioners and non-practitioners regarding the proposed relationships between the psychological constructs and PEB. Furthermore, in the discussion on mindfulness as a pathway to PEB, mindfulness related individual well-being is often suggested to be an important 
accompanying motivational factor (Ericson et al., 2014; Geiger et al., 2019; Hunecke, 2018; Kasser, 2017; Thiermann and Sheate, 2020b). Therefore, we additionally investigated mindfulness as a predictor of different daily well-being measures, namely positive and negative affect, satisfaction with day and meaning presence.

\subsection{Daily Pro-environmental Behavior}

The explanation of individual PEB is one of the key questions in environmental research (Steg and Vlek, 2009). In general, order to measure PEB, self-report scales that include different environmental significant behaviors are usually conceptualized and applied either as a one-dimensional (Kaiser, 1998) or as a multidimensional measure with different behavioral domains such as nutrition, consumption, energy use and mobility behavior (Bratt et al., 2015; Geiger et al., 2018; Markle, 2013). Another approach is to structure the PEB by occurring frequencies that can be best assessed through self-report diary studies (Lange and Dewitte, 2019). There are only a few examples for the use of diary methods to assess environmentally relevant behaviors. These can be found in the areas of mobility behavior (Hilgert et al., 2018), recycling behavior (Chu and Chiu, 2003) and energy conservation (Maleetipwan-Mattsson et al., 2013). A daily diary study by Bissing-Olson et al. (2013) investigated daily pro-environmental behavior at work, included daily affect as an additional daily varying variable and found a positive relationship between activated positive affect and proactive PEB. The described study demonstrates that daily diary studies are especially interesting when investigating proximate and day-to-day varying predictors for PEB. In this regard, the role of daily psychological states as potential predictors of PEB in every-day life is interesting. Furthermore, a daily diary approach can meet some of the methodological weaknesses of cross-sectional study designs and problems that are often related to common instruments that measure PEB by self-report (Lange and Dewitte, 2019). First, through more than one measurement, the results do not entirely rely on a single report and may therefore be more accurate. This may be not only due to the 
repeated measurement, but also through the temporal proximity to the actual behavior. Second, this temporal proximity and repeated measurement furthermore enables a more fine-grained investigation of intrapsychological processes that are suggested to be related to PEB.

\subsection{Mindfulness and Mind-body Practice}

Mindfulness has been defined as a form of awareness, which is nonjudging, anchored in the present moment and on purpose (Kabat-Zinn, 1990). Bishop et al. (2004) suggested a two-component model to describe mindfulness. The first element is the ability to self-regulate attention, which includes the ability to sustain and shift the attentional focus. The second element is a stance, where all emerging experiences are perceived with an open and accepting attitude. The mindfulness concept has gained considerable attention in the last decades, especially in application fields to increase health and reduce stress (Grossman et al., 2004). One of the key mechanism of mindfulness has been identified as decentering or reperceiving, respectively (Shapiro et al., 2006). It can be described as a metacognitive capacity that allows a shift in perspective in order to observe subjective experiences as a witness without the identification and reactivity to their content (Bernstein et al., 2015). Thereby habitual reactive patterns are interrupted and cognitive, emotional and behavioral flexibility is enhanced. As a consequence reflective processes can evolve, that may initiate for example a clarification of values on the long-term (Shapiro et al., 2006). The identified mechanisms of mindfulness suggest that mindfulness can have an influence not only in the present moment, but also beyond by opening up potentials for cognitive, emotional and behavioral changes.

In general, mindfulness is often conceptionalized and operationalized as a relatively stable psychological trait between individuals, respectively a general tendency to be mindful more or less mindful. However, within individuals the degree of mindfulness can vary when looking at different time frames such as days and situations (Brockman et al., 2017; Friese and Hofmann, 2016). Therefore, the 
investigation of covariating psychological constructs and behaviors may give more fine-grained insights into potential effects of mindfulness variations.

Besides this conceptualization of mindfulness as a psychological construct, mindfulness can be understood as a type of practice. This practice of mindfulness includes meditation or body-orientated meditation types such as mindful walking or yoga. In the present study, we summarize those meditation forms as mind-body practices (MBP). While some studies found MBP to enhance trait mindfulness (Eberth and Sedlmeier, 2012; Kiken et al., 2015), others did not observe such an increase through mindfulness-based programs and point out to difficulties in assessing mindfulness practices with selfreports (Visted et al., 2015). However, in regular mind-body practitioners often higher levels of trait mindfulness are present (e.g. Baer et al., 2008). Also, it is likely that the mindfulness measure is understood differently by mind-body practitioners in contrast to practice-naïve individuals (Rudkin et al., 2018). One aim of MBP is usually to be and act more consciously not only during the formal practice but also beyond in every-day life. Therefore, it seems likely that for regular practitioners, mindfulness plays a specifically important role regarding psychological experiences and behavior decisions in every-day life. Also, as regular MBP practitioners often actively pursuit to heighten mindfulness, day-to-day variations of mindfulness may be easier to observe in practitioners (Snippe et al., 2015).

\subsection{Mindfulness and Pro-environmental Behavior: Mechanisms and Mediators}

Mechanisms of the empirical identified correlational relationship between mindfulness and PEB have been extensively discussed theoretically (Ericson et al., 2014; Geiger et al., 2019; Hunecke, 2020; Thiermann and Sheate, 2020b). In this context, situational effects of mindfulness such as deautomatization of consumption choices are suggested as well as potentials of mindfulness to support the development of non-materialistic values, meaning and connectedness to nature and others are. 
Some suggestions have been already empirically confirmed to mediate the connection between trait mindfulness and PEB. For example, pro-sociality and connectedness to others (Loy and Reese, 2019; Panno et al., 2018), connectedness to nature (Barbaro and Pickett, 2016; Hanley et al., 2020), the decrease of materialistic values (Brown and Kasser, 2005; Geiger et al., 2020), health and well-being (Geiger et al., 2020; Geiger et al., 2017), as well as meaning construction (Hunecke and Richter, 2019). In contrast, a proposed heightened congruence between attitude and behavior could not be confirmed in an intervention study by Geiger et al. (2020). Other postulated potentials of mindfulness which may foster PEB but which are, up to now, not empirically validated are the sensitization for one's body sensations, increasing of self-acceptance, deautomatization of behaviors and openness for new experiences (Hunecke, 2020).

Beside those mechanisms, there is evidence that the facets of mindfulness do differ in their relationship to PEB. Most consistently, the dimension of observing was found to be significantly correlated to PEB (Geiger et al., 2019) and to PEB-related variables, such as personal ecological norms and attitude (Richter and Hunecke, 2020). Observing can be described as the awareness of inner and outer stimuli such as sensations, cognitions, emotions, sights, sounds, and smells (Baer et al., 2008). The facet of observing has been discussed as the essential aspect of mindfulness (Lilja et al., 2013) and has been also found to have a particularly strong relationship with connectedness to nature (Barbaro and Pickett, 2016).

To summarize, there have been a number of theoretical suggestions and empirically confirmed mediators of the mindfulness-pro-environmental behavior connection. However, empirical evidence does exist, but is limited with regard to the small number of investigations and cross-sectional study designs. 


\subsection{Connectedness to Nature and Personal Ecological Norm}

As described above, one pathway to explain the relationship between trait mindfulness and proenvironmental behavior is through nature connectedness, where especially the mindfulness facet of observing was identified as particularly relevant (Barbaro and Pickett, 2016). Connectedness to nature is described as the subjective feeling of communion with nature as well as to see oneself as a part of nature (Mayer and Frantz, 2004). As a basis for the development of nature connectedness, especially the regular contact to nature is seen as important (Cleary et al., 2020). Dispositional mindfulness and observing, meditation in nature or with natural elements was also found to enhance connectedness to nature (Ray et al., 2020; Unsworth et al., 2016). One explanation for this connection is that highly mindful individuals may observe natural environments and their emotional and cognitive responses while being in contact to nature more consciously. This conscious observing, especially of positive experiences with nature might be a basis to develop a feeling of nature connectedness. Studies show furthermore that nature connectedness is related to hedonic as well as eudaimonic types of well-being, such as positive affect, life satisfaction, vitality and meaning in life (Capaldi et al., 2014; Howell et al., 2013; Mayer et al., 2009; Nisbet et al., 2011). Aside from the positive effects of connectedness to nature for well-being, numerous studies identified a correlation between connectedness to nature and PEB (Mackay and Schmitt, 2019) and PEB-related variables such as intentions, moral norms, attitudes (Sparks et al., 2014) and biospheric values (Martin and Czellar, 2017). One explanation for the relationship between connectedness to nature and PEB might be the feeling of personal moral obligation to protect the environment that is developed as a consequence of feeling connected to nature.

The personal ecological norm, which activates a feeling of obligation to behave in an environmentally friendly way, is the central construct the Norm-Activation-Theory (NAM) by Schwartz (1977) as well as in the Value-Belief-Norm (VBN) Theory of Environmentalism (Stern et al., 1999). Also, the role of a personal ecological norm has been empirically confirmed as distinct from other important PEB-predictors 
(Bamberg and Möser, 2007; Thogersen and Olander, 2006). With regard to mindfulness, a study by Hunecke and Richter (2019) identified the personal ecological norm as one mediator between the mindfulness facet of observing and the consumption of sustainable foods. Therefore, the further investigation of the connection between mindfulness and personal ecological norm as a mediator on a daily level is purposeful. While mindfulness as well as connectedness to nature have already been investigated on a state level (Friese and Hofmann, 2016; Mayer et al., 2009), personal norms are usually seen as a stable construct that are close to personal values (Schwartz, 1977). Although it cannot be expected that the general personal ecological norm varies in the short-term, it is conceivable that the activation of one's personal norm is not always salient to the same degree and therefore varies between situations and days. Thus, the investigation of the daily activation of feelings of personal obligation to act pro-environmentally could be interesting. In the following we use the term personal ecological norm activation (PENA) when referring to daily feelings of obligation to behave pro-environmentally.

\subsection{Mindfulness and Well-Being}

As the enhancement and maintenance of individual well-being is important for most individuals, mindfulness has been discussed as a promising pathway not only to increase PEB, but at the same time individual well-being (Ericson et al., 2014; Geiger et al., 2019; Hunecke, 2018; Kasser, 2017; Thiermann and Sheate, 2020b). Mindfulness-based programs are not only effectively used in clinical contexts (Goldberg et al., 2018), also in non-clinical contexts the psychological construct of mindfulness was found to be related to personal well-being, including hedonic and eudaimonic approaches to well-being (Richter and Hunecke, 2020). While the hedonic approach to well-being focuses on the experience of pleasure, positive affect and the avoidance of negative emotional states, the eudaimonic approach usually puts an emphasis on aspects such as self-realization and purpose in life (Huta and Waterman, 2014). In the following, the term well-being is used as a superordinate term for approaches to well-being 
and happiness, including hedonic and eudaimonic aspects. On a within-person level, a number of studies identified positive connections between mindfulness and same-day affective well-being (Brockman et al., 2017; Mahlo and Windsor, 2021). Furthermore, a study by Snippe et al. (2015) found that day-to-day changes in mindfulness predicted subsequent day-to-day changes of positive and negative affect during a mindfulness-based stress reduction (MBSR) program. This points out to potential effects of mindfulness beyond one day. As most studies focus primarily on affective well-being when investigating mindfulness on a daily level, it is additionally interesting to investigate further well-being measures that may be related to mindfulness. In this context, the cognitive evaluation of one's satisfaction with the day or eudaimonic aspects, such as the experience of meaningfulness are interesting.

\subsection{Purpose of the Present Study}

Mindfulness has been found to be positively correlated to private-sphere pro-environmental behaviors and it is increasingly discussed. However, none of the previous studies investigated mindfulness and those behaviors on a daily within-person level. The investigation of mindfulness on a daily level can give further insights as to the intrapersonal relevance of daily mindfulness with regard to pro-environmental behavior and other behaviorally-relevant variables such as connectedness to nature and the activation of the personal ecological norm. At the same time, there is evidence that mindfulness is not only connected to PEB but is stabilizing personal well-being simultaneously. However, previous studies investigating mindfulness and well-being on a within-person level focused mostly on affective components of well-being (e.g. Brockman et al., 2017). Therefore, less is known about the intrapersonal connections of mindfulness to other well-being measures, such as daily satisfaction or meaning presence.

To get more insights into those relationships on a within-person level, the present study investigates daily relationships between mindfulness and PEB with a focus on connectedness to nature, 
PENA and well-being. As the mindfulness facet of observing was consistently found to be a significant predictor for PEB and connectedness to nature in previous studies, we put an emphasis on this facet of mindfulness and additionally analyze it separately. Furthermore, we used a new daily PEB-measure as a dependent variable that consists of daily behaviors. In order to consider the impact-perspective of PEB, we only include behaviors that have an ecological impact.

The first research question (RQ1) focuses on whether mindfulness is a predictor of same-day PEB, PENA, connectedness to nature and well-being (negative and positive affects, satisfaction with day and meaning presence). We propose that mindfulness and the mindfulness dimension of observing are significantly related to those variables within a day. Second, processes initiated by high mindfulness, such as cognitive and behavioral flexibility as well as the activation of values might have a lasting effect beyond one day. Therefore, the second research question (RQ2) focuses on whether potential timelagged effects of mindfulness and observing can be found. Because a temporal precedence can be seen as an indicator for causality (West and Hepworth, 1991), time-lagged analyses could give insights into potential causal influences of mindfulness on the proposed variables. The third research question (RQ3) focuses on whether MBP moderates the relationship between mindfulness and PEB, connectedness to nature, PENA and the well-being measures. The combination of MBP with high mindfulness may have a greater impact in daily life for regular mind-body practitioners. Therefore, we hypothesize that for regular mind-body practitioners, the proposed same-day relations between mindfulness and observing, PEB, PENA, connectedness to nature and well-being are stronger. The fourth research question (RQ4) focuses on the test of the proposed relationships and investigates connectedness to nature and PENA as potential mediators of the connection between mindfulness and PEB on within-person and betweenperson level. 


\section{Method}

The plan for the study was preregistered prior data collection at OSF ( https://osf.io/4te5b/?view only=63de5ee7762649408cf2e8ad5d697ec2). A report regarding deviations from the preregistration, the full questionnaire, data, $\mathrm{R}$ scripts and the preregistration of the data exclusion plan can be found in the corresponding OSF project (https://osf.io/pw7zs/?view only=c313667dc41f401593a29ef1fd4ae460).

\subsection{Power Analysis}

As in multilevel-models many factors influence the statistical power and power analyses for multilevel-models are complex to perform. In case of daily diary data, days (level 1) are nested within participants (level 2) in the analyses. Simulation studies suggest that the number of level two variables (participants) is more influential than level one variables (days) and cross-level interactions require a greater sample size than analyses on within-person level (Maas and Hox, 2005). For within-person analyses, a sample size of approximately 100 participants is recommended (Ohly et al., 2010). As our main hypotheses were on the within-person level, we aimed to collect data from at least 100 individuals (a minimum of 50 mind-body practitioners and 50 mind-body practice naïve individuals). To ensure a minimum of representativeness of the data with regard to the target groups, we aimed to collect completed diaries for 7 days from 150-250 individuals.

\subsection{Data Exclusion}

The criteria for the exclusion of data was oriented towards the recommendations by Nezlek (2012). Overall, 199 people participated in the study and completed daily questionnaires. Participants and their daily questionnaires were removed if they did not answer the quality-check items correctly in the pre-questionnaire and showed further inconsistencies and wrong quality-check items in the daily questionnaires ( 8 participants). Further, participants were removed if they reported critical life events 
during the study period in the post-questionnaire ( 5 participants), if they filled out less than three daily questionnaires ( 2 participants) or completed less than two consecutive days ( 1 participant). Additionally, daily questionnaires with wrong answers on the quality-check item were excluded ( 5 daily questionnaires), when a critical event was reported (e. g., sickness or moving, 4 participants) or the daily questionnaire was completed outside the scheduled period ( $8 \mathrm{pm}$ to 4 am, 1 daily questionnaire). The final sample consisted of 183 participants (level 2) and 1197 days (level 1).

\subsection{Participant Characteristics}

Regarding the participants included in the analysis, 148 (82.0\%) of the participants were female, $30(16.4 \%)$ male, $2(1.1 \%)$ assigned themselves as diverse and $3(1.6 \%)$ provided no information about their gender. Participants were on average $39.3(S D=13.66)$ years old with an average income of 2282 Euros $(S D=1528, n=151)$. A majority of $104(56.8 \%)$ participants had a university degree and $56(30.6 \%)$ reported a higher education entrance qualification. Of the participants, 48 (26.2\%) were part-time employed, 44 (24.0\%) full-time employed and 35 (19.0\%) were undergraduate students. Further information regarding the sample characteristics can be found in the supplementary materials (Tables A to C). The time required to complete the questionnaire was mostly around 5 minutes ( $M d n=5.75, M=$ $14.29, S D=106.21)$. Most participants completed seven daily questionnaires during the participation period $(M=6.54, S D=0.98, M d n=7)$. Most of the daily questionnaires were filled out between $8-9 \mathrm{pm}$ ( $n=449)$, between 9-10 pm $(n=275)$ and 10-11 pm $(n=260)$. The number of completed questionnaires was distributed over the weekdays as follows: Monday: $n=167$, Tuesday: $n=162$, Wednesday: $n=172$, Thursday: 178 , Friday: $n=168$, Saturday: $n=167$ and Sunday: $n=183$.

\subsection{Sampling Procedure}

We aimed to collect seven daily questionnaires from each of the participants over a maximum study period of 10 days. Furthermore, all psychological variables as well as PEB were additionally measured in a 
pre-questionnaire. The study procedure is depicted in Figure 1. The study period started at the end of October 2020 and was closed in the middle of December. Potential participants were invited to take part in a daily diary study via online social networks, meditation centers and advertisements in local magazines. We specifically invited participants with regular MBP as well as participants with no MBP experience at all. Interested individuals who visited the study start page were first informed as to the aims of the study, the procedure, data security and the study compensation which consisted of a lottery with 20 books for participants who completed 7 daily questionnaires. Participants who completed at least 5 daily questionnaires received individual anonymous statistics of their study data. Participants needed to confirm that they were at least 18 years old and after the confirmation of informed consent through a link via E-Mail, they received an invitation to complete the pre-questionnaire which took about 20 minutes to complete. Once the pre-questionnaire was completed, the invitation with the first daily questionnaire was sent on the next day at $8 \mathrm{pm}$, reminders were sent at $10 \mathrm{pm}$ and the questionnaire remained open until 4 am. Overall, participants received invitations to the daily questionnaire for a period of maximum nine days and were subsequently invited to complete the final questionnaire. If they finished seven daily questionnaires at an earlier time, they were directly sent to the final questionnaire. For the technical realization of the daily diary study the survey framework formr (Arslan et al., 2020) was used. All questionnaires could be filled out on a smartphone as well as an internet browser. 
Figure 1

Study Procedure

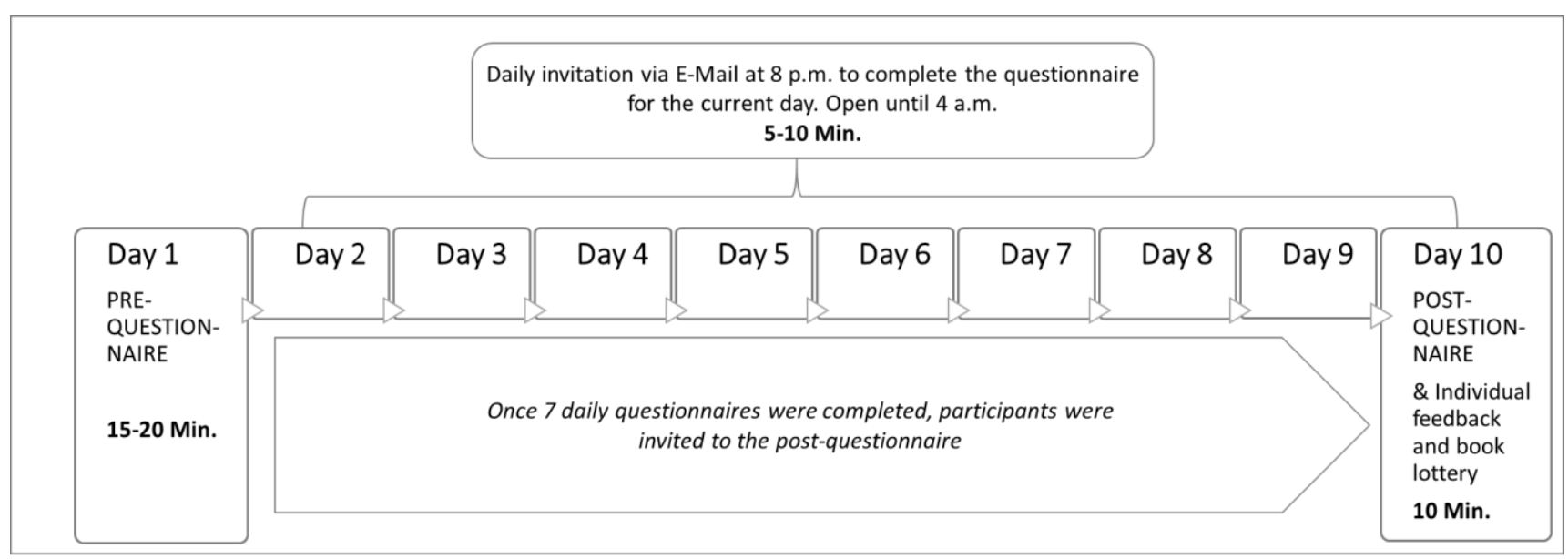

\subsection{Measures}

Each psychological construct was measured in the pre-questionnaire and adapted to a daily format for the daily questionnaire. The descriptive statistics, intra-class correlations and reliabilities are summarized in Table 1. 
MINDFULNESS AND PRO-ENVIRONMENTAL BEHAVIOR IN A DAILY DIARY STUDY

Table 1

Descriptive Statistics, Intra-Class Correlations and Reliabilities of Study Measures

\begin{tabular}{|c|c|c|c|c|c|c|c|c|c|c|}
\hline Questionnaire & Scale & $M$ & $S D$ & ICC & $\omega$ & & $\alpha$ & $\mathrm{n}$ & $\min$ & $\max$ \\
\hline \multirow[t]{9}{*}{ Daily } & Mindfulness & 3.64 & 0.70 & 0.72 & Lvl 1: 0.68 & Lvl 2: 0.95 & - & 1194 & 1.14 & 5.00 \\
\hline & Observing & 3.48 & 0.88 & 0.69 & Lvl 1: 0.66 & Lvl 2: 0.95 & - & 1197 & 1.00 & 5.00 \\
\hline & PEB & 62.83 & 21.56 & 0.54 & - & - & - & 1197 & 0.00 & 100 \\
\hline & PENA & 3.12 & 1.29 & 0.77 & Lvl 1: 0.70 & Lvl 2: 0.97 & - & 1189 & 1.00 & 5.00 \\
\hline & $\begin{array}{l}\text { Connectedness to } \\
\text { Nature }\end{array}$ & 3.13 & 1.08 & 0.57 & Lvl 1: 0.73 & Lvl 2: 0.87 & - & 1197 & 1.00 & 5.00 \\
\hline & Positive Affect & 3.38 & 0.96 & 0.54 & Lvl 1: 0.81 & Lvl 2: 0.94 & - & 1195 & 1.00 & 5.00 \\
\hline & Negative Affect & 2.07 & 0.94 & 0.53 & Lvl 1: 0.69 & Lvl 2: 0.89 & - & 1197 & 1.00 & 5.00 \\
\hline & Life Satisfaction & 4.96 & 1.54 & 0.50 & - & - & - & 1195 & 1.00 & 7.00 \\
\hline & Meaning Presence & 4.75 & 1.57 & 0.55 & - & - & - & 1195 & 1.00 & 7.00 \\
\hline \multirow[t]{9}{*}{ Pre } & Mindfulness & 3.39 & 0.65 & - & total: 0.97 & $\mathrm{~g}: 0.36$ & 0.96 & 183 & 1.41 & 4.77 \\
\hline & Observing & 3.81 & 0.69 & - & total: 0.87 & g: 0.31 & 0.82 & 183 & 1.50 & 5.00 \\
\hline & PEB & 3.81 & 0.49 & - & 0.84 & - & 0.76 & 183 & 2.17 & 4.83 \\
\hline & Personal Norm & 4.17 & 0.81 & - & 0.87 & & 0.87 & 183 & 1.33 & 5.00 \\
\hline & $\begin{array}{l}\text { Connectedness to } \\
\text { Nature }\end{array}$ & 3.72 & 0.63 & - & 0.86 & & 0.87 & 183 & 1.93 & 4.71 \\
\hline & Positive Affect & 3.38 & 0.97 & - & 0.94 & & 0.94 & 183 & 1.33 & 5.00 \\
\hline & Negative Affect & 2.67 & 0.94 & - & 0.88 & & 0.88 & 183 & 1.00 & 5.00 \\
\hline & Life Satisfaction & 4.52 & 1.42 & - & 0.90 & & 0.90 & 183 & 1.20 & 7.00 \\
\hline & Meaning Presence & 3.45 & 1.20 & - & 0.93 & & 0.93 & 182 & 1.00 & 5.00 \\
\hline \multirow[t]{4}{*}{ Post } & COVID-19-threat: & & & & & & & & & \\
\hline & Professional future & 2.95 & 1.06 & & - & & - & 182 & 1.00 & 5.00 \\
\hline & Life Quality & 2.03 & 1.27 & & - & & - & 183 & 1.00 & 5.00 \\
\hline & Health & 2.59 & 1.14 & & - & & - & 183 & 1.00 & 5.00 \\
\hline
\end{tabular}




\subsubsection{Mindfulness}

General mindfulness was measured using parts of the Five Facet Mindfulness Questionnaire (FFMQ) (Baer et al., 2008; Michalak et al., 2016) and the Comprehensive Inventory of Mindfulness Experiences (CHIME) (Bergomi et al., 2014). The four mindfulness dimensions nonjudging, nonreactivity, describing, and acting with awareness were assessed using 31 items of the FFMQ. Because of the focus on the aspect of observing in the present study, we used the two dimensions of the CHIME inner awareness (5 items) and outer awareness ( 3 items), as it is more differentiated than the observing facet in the FFMQ. One item of the outer awareness subdimension was not included in the survey due a technical mistake. In order to justify the summary as one mindfulness mean value, a bifactorial CFA with all six mindfulness dimensions and all 39 items was tested. The model yielded acceptable and some slightly non-acceptable indices (CFI $=.93, \mathrm{TLI}=.92 . \mathrm{RMSEA}=.052,90 \% \mathrm{Cl}[.04, .06], \mathrm{SRMR}=.057, \mathrm{~N}=$ 171). In sum, 35 items were significantly related to a general mindfulness factor. Two items of the mindfulness dimension of outer awareness (CHIME), one item of the inner awareness dimension (CHIME) and one item of the describing dimension (FFMQ) showed no significant correlated to the general mindfulness factor. However, for the sake of completeness and comparability with other studies, they were not excluded. To test the factorial structure of the mindfulness aspect of observing, a bifactor model with observing as the general factor and the two dimensions of the CHIME inner awareness and outer awareness as latent variables was tested. The model yielded a good fit (CFI $=1.00, T L I=1.05$, RMSEA $=.000,90 \% \mathrm{Cl}[.00, .07], \mathrm{SRMR}=.018, N=179)$ and all items with the exception of two were significantly related to the general observing factor.

For the daily format, 2 to 3 items of each dimension were selected based on previous experience in sampling studies (Eisenlohr-Moul et al., 2016; Gotink et al., 2016), by the highest factor loadings (Bergomi et al., 2014) as well as theoretical considerations and were adapted to a daily format (e.g. 
"Today, when sitting or lying down, I was aware of my body sensations"). Items were rated on a 5-point scale $(1=$ never or very seldom to $5=$ very often or always applicable $)$.

\subsubsection{Connectedness to Nature}

Nature connectedness was measured using the connectedness to nature scale (CNS, e.g. "I think of the natural world as a community to which I belong"), which comprises 14 items (Brügger et al., 2011; Mayer and Frantz, 2004). Daily connectedness to nature was assessed by three items of the CNS that were adapted to a daily format (e.g. "I felt connected to nature today") that were rated on a 5-point scale $(1=$ very seldom or never to $5=$ very often or always applicable $)$.

\subsubsection{Affective Well-being}

Positive and negative affect were measured using the Scale of Positive and Negative Experience (SPANE; Diener et al., 2009) which comprises positive affects and negative affects with six items per dimension. For the daily version overall six items of SPANE were included, for each aspect three items (e.g. "happy", "sad") were included and the instruction was adapted to the current day ("Please indicate in the following list how often you have felt like this today"). The items were rated on a 5-point scale (1 = very rarely or never to 5 = very often or always).

\subsubsection{Presence of Meaning}

In the pre-questionnaire was measured by the dimension of meaning presence of the Meaning in Life Questionnaire (MLQ; Steger et al., 2006), which comprises five items (e.g. "My life has a clear sense of purpose"). The daily presence of meaning was asked using one item (e.g. "Overall I experienced my day as meaningful") that was rated on a 7-point scale $(1=$ does not apply at all to $7=$ very often or always). 


\subsubsection{Satisfaction with Life and Day}

Overall life satisfaction was measured by the 5 -item Satisfaction With Life Scale (SWLS; Diener et al., 1985; Glaesmer et al., 2011; e.g. "I am satisfied with my life”). Daily satisfaction was assessed by one item ("Overall, I am satisfied with my day.") and was rated on a 7-point scale ( 1 = does not apply at all to $7=$ very often or always).

\subsubsection{Personal Ecological Norm}

Environment-related personal norms were assessed using three items formulated on the basis of the personal norm of the NAM (Schwartz, 1977; e.g. "It is my personal responsibility to behave as climate-friendly as possible in my everyday life"). Daily PENA was measured by two items with reference to the current day (e.g. "Today I felt that I should act in an environmentally friendly way"). The Items were rated on a 5 -point scale $(1=$ very seldom or never to $5=$ very often or always applicable $)$.

\subsubsection{Pro-environmental Behavior}

In the pre-questionnaire, PEB was assessed with 16 items overall, using a 5-point rating scale ( $1=$ never to $5=$ always). Participants were asked to relate their answers to the previous four weeks. Two energy items were removed to increase comparability with the daily PEB measurement (see below). Furthermore, two of the mobility items were not included in the final scale because many participants reported avoiding public transport or carpooling due to the COVID-19 pandemic. The final scale included 12 items in the behavior domains of nutrition ( 2 Items, e.g. "I avoid meat in my diet"), food consumption (3 Items, e.g. "When buying groceries, I prefer certified organic food products"), general consumption (2 Items, e.g. "I buy second-hand items, such as clothes or books"), energy ( 2 Items, e.g. "When I leave the house, I turn off all sources of energy that I do not need (e.g. lights, stand-by devices)"), trash (2 Items, e.g. "I avoid disposable packaging (e.g. coffee cups, plastic packaging)") and mobility (1 Item, "Short 
distances up to 3 kilometers I do by walking or by bike"). A higher order model with a general factor and those six action domains as subfactors and yielded a good fit $(\mathrm{CFI}=.98, \mathrm{TLI}=.97$. $\mathrm{RMSEA}=.037,90 \% \mathrm{Cl}$ $[.00, .07]$, SRMR $=.054, N=180)$.

Daily pro-environmental behavior was assessed by categorial variables including nutrition, food consumption, energy and mobility behaviors. Behaviors queried daily were chosen based on the following criteria: (1) the behavior has a measurable ecological impact, (2) the behavior can be chosen mostly on a daily basis, (3) the behavior is a positive behavior option (e.g. to choose a vegetarian meal instead abstaining from meat). We identified 21 behaviors that met those criteria. As the individual daily options for behaviors vary each day, participants were first asked general questions with regard to their day: the number of meals they had, if they had bought groceries, how many kilometers they had travelled and if they had avoided public transport or carsharing due to the COVID-19 pandemic. Based on their answers, a number of possible behaviors were presented that could be mostly answered with yes or no. In order to get a comparable measure of daily PEB, the proportion of realized behaviors compared to the number of possible behaviors was calculated as a percentage. For example, if 10 proenvironmental behaviors were possible on a day and 6 of those behaviors were realized, on this day the person would have a PEB value of $60 \%$. In the open text fields, participants wrote 14 comments regarding two items from the area of energy use (a decrease of streaming and the use of an ecological search engine), which indicated that many participants did not understand those items correctly. Therefore, the two energy use items were excluded from the analyses.

\subsubsection{Mind-body Practice}

The participants were asked in the pre-questionnaire, whether they had experience with MBP and if they currently practiced regularly (at least once a weak). Participants who regularly practiced mindfulness meditation or meditative body work (e.g. yoga) were assigned to the mind-body practitioner 
group $(n=52)$ and participants who had no experience at all to the practice-naïve group $(n=45)$. Practitioners reported higher levels of daily mindfulness $(M=3.94, S D=0.54)$ compared to practicenaïve participants $\left(M=3.45, S D=0.67, t(95)=-4.03, p<.001, d_{\text {cohen }}=.82\right)$. Also, daily observing was on average higher in practitioners $(M=3.86, S D=0.65)$ compared to practice-naïve participants $(M=3.18$, $\left.S D=0.84, \mathrm{t}_{\text {welch }}(82.6)=-4.38, \mathrm{p}<.001, d_{\text {cohen }}=.91\right)$.

\subsubsection{Daily Nature Contact}

Participants were asked every day if they spent time in nature for example in forests, parks, gardens, fields and lakes/sea (options: Yes or No).

\subsubsection{COVID-19-Threat}

Because the study was conducted during the COVID-19-pandemic from October to December 2020, we include some questions regarding perceived threats through the pandemic. Even if pandemicrelated restrictions were not as new as at the beginning of the pandemic, we assume that the felt threat through the pandemic still had an influence at that time on people's daily behavioral priorities, routines, and psychological experiences. To be able to statistically control some of the corona-related effects on people's daily lives, we asked in the post-questionnaire participants how strongly they felt threatened by the COVID-19 pandemic during the study participation period with regard to their life quality, professional future and health (e.g. "How much did you feel your quality of life was threatened by the corona crisis?"), rated on a scale from 1 no threat at all to 5 highly threatened.

\subsection{Analytic Strategy}

All analyses were conducted using the R environment 3.6.0 (R Core Team, 2020). To estimate the internal consistencies of the scales for the level 1 variables, omega was calculated for both levels as suggested by Geldhof et al. (2014). Additionally to Cronbach's- $\alpha$, for all constructs of the pre- 
questionnaire with more than one item Macdonald's omega was estimated. The model fit for the CFA was evaluated using the Comparative Fit Index (CFI), Tucker-Lewis-Index, Root Mean Square Error of Approximation (RMSEA) as well as Standardized Root Mean Square Residual (SRMR). A CFI and TLI of $\geq$ .95 , an RMSEA, and an SRMR of $\leq .08$ indicate a good fit (Hu and Bentler, 1999). Further, correlations between the daily means and the pre-questionnaire means were calculated. For this purpose, the daily questionnaires were grouped by person.

The proposed same-day relationships (RQ1), were analyzed with multilevel regression models using the Ime4 (Bates et al., 2015) and ImerTest (Kuznetsova et al., 2017). To analyze time-lagged effects of mindfulness on the proposed dependent variables (connectedness to nature, PENA, PEB, positive affect, negative affect, satisfaction with day and meaning presence) at a time point ( $\left.t_{\text {day }}\right)$, previous day $\left(t_{\text {day }}-1\right)$ mindfulness respectively observing were included as time-lagged predictors in the models. To control for the effect of the dependent variable itself, the time-lagged respective dependent variable was also included (e.g. PEB of the previous day). As not for all daily values the values from the preceding day is available (e.g. the first day of the study or if a daily questionnaire was skipped), it was possible to include 986 to 1002 days in the different models. In a next step, the temporal precedence of the variables was analyzed in the reverse direction in order to verify indication of causality (Nezlek et al., 2017). For this purpose, mindfulness and observing, respectively, were modeled as a dependent variable and the other variables were entered as time-lagged predictors (e.g. PEB of the previous day predicts mindfulness). If the connections were not found inversely, the results would indicate time-lagged effect on the proposed variables. As the effects of level-1 predictors in autoregressive models are likely to be negatively biased (Hamaker and Grasman, 2014), we did not person-mean center the variables included in the lagged models. 
The moderation effects (RQ3) were tested using a subsample $(n=95)$ with mind-body practice naïve participants $(n=45)$ and regular practitioners $(n=52)$. All other participants were excluded from these analyses. Interaction terms (mindfulness $x$ MBP respectively observing $x \mathrm{MBP}$ ) were included as predictors in the multilevel regression models.

All of the multilevel regression models to analyze RQ1, RQ2 and RQ3 included age, nature contact and three COVID-19-threat items as control variables. Due to pairwise exclusion, the sample size varies in the analyses. Metric level-1 predictors were previously person-mean centered and level-2 predictors were grand-mean centered. Standardized beta weights were calculated by previously standardizing the metric variables and testing the same models (Lorah, 2018). Metric level-1 predictors were person-mean centered after standardizing. The proposed path model and mediation effects were tested using multilevel structural equation modeling for the daily diary data and using a path model for the pre-questionnaire data with the R-package lavaan (Rosseel, 2012). 


\section{Results}

An overview of the intercorrelations between the daily measures and the pre-questionnaire measures is depicted in Table 2.

\subsection{Same-day Within-person Relationships Between Mindfulness, Connectedness to Nature, PENA, PEB and Well-being}

The proposed relationships between daily mindfulness and the proposed dependent variables were tested in separate models. Additionally, the same models were tested using the mindfulness facet of observing instead of mindfulness as predictor. A comparison between random-intercept and randomslope models yielded a better fit for 8 of the 14 models, but this was only highly significant for three models ( $p<.001)$. Therefore, we decided to consistently use the less complex random-intercept models. As hypothesized, mindfulness as well as observing predicted connectedness to nature ( $\beta_{\text {Mindfulness }}=.48$, $\left.p<.001 ; \beta_{\text {observing }}=.47, p<.001\right)$ and PENA $\left(\beta_{\text {Mindfulness }}=.15, p<.001 ; \beta_{\text {observing }}=.15, p<.001\right)$ significantly . There were no significant relationships between mindfulness and observing with PEB ( $\beta_{\text {Mindfulness }}=-.04, p$ $\left.=.314 ; \beta_{\text {observing }}=.15, p<.001\right)$. Furthermore, strong effects of mindfulness as a predictor of well-being were found for positive affect ( $\beta_{\text {Mindfulness }}=.63, p<.001$ ), negative affect $\left(\beta_{\text {Mindfulness }}=-.55, p<.001\right)$ and satisfaction with day ( $\left.\beta_{\text {Mindfulness }}=.61, p<.001\right)$. For reasons of a compact result presentation, Tables 3 and 4 show only the main effects of interest. The full models can be accessed in the supplementary materials (Tables D and G). 
MINDFULNESS AND PRO-ENVIRONMENTAL BEHAVIOR IN A DAILY DIARY STUDY

\section{Table 2}

Correlations for Pre-Questionnaire and Person-Aggregated Daily Diary Variables

\begin{tabular}{|c|c|c|c|c|c|c|c|c|c|c|c|c|c|c|c|c|c|c|}
\hline & & 1 & 2 & 3 & 4 & 5 & 6 & 7 & 8 & 9 & 10 & 11 & 12 & 13 & 14 & 15 & 16 & 17 \\
\hline & Pre-Questionnaire & & & & & & & & & & & & & & & & & \\
\hline 1 & Mindfulness & 1 & & & & & & & & & & & & & & & & \\
\hline 2 & Observing & $.73^{* *}$ & 1 & & & & & & & & & & & & & & & \\
\hline 3 & PEB & $.24^{* *}$ & $.27^{* *}$ & 1 & & & & & & & & & & & & & & \\
\hline 4 & Personal norm & $.20^{* *}$ & $.31^{* *}$ & $.57^{* *}$ & 1 & & & & & & & & & & & & & \\
\hline 5 & Connectedness to nature & $.37^{* *}$ & $.52^{* *}$ & $.38^{* *}$ & $.51^{* *}$ & 1 & & & & & & & & & & & & \\
\hline 6 & Positive Affect & $.58^{* *}$ & $.43^{* *}$ & $.23^{* *}$ & $.27^{* *}$ & $.30^{* *}$ & 1 & & & & & & & & & & & \\
\hline 7 & Negative Affect & $-.54^{* *}$ & $-.24^{* *}$ & $-.19^{*}$ & $-.20^{* *}$ & -.14 & $-.77^{* *}$ & 1 & & & & & & & & & & \\
\hline 8 & Satisfaction with life & $.59^{* *}$ & $.37^{* *}$ & $.16^{*}$ & .13 & $.19^{* *}$ & $.76^{* *}$ & $-.64^{* *}$ & 1 & & & & & & & & & \\
\hline \multirow[t]{2}{*}{9} & Meaning presence & $.65^{* *}$ & $.49^{* *}$ & $.19^{* *}$ & $.25^{* *}$ & $.34^{* *}$ & $.60^{* *}$ & $-.46^{* *}$ & $.69^{* *}$ & 1 & & & & & & & & \\
\hline & Daily Diary & & & & & & & & & & & & & & & & & \\
\hline 10 & Mindfulness & $.80^{* *}$ & $.72^{* *}$ & $.33^{* *}$ & $.30^{* *}$ & $.44^{* *}$ & $.53^{* *}$ & $-.46^{* *}$ & $.49^{* *}$ & $.60^{* *}$ & 1 & & & & & & & \\
\hline 11 & Observing & $.66^{* *}$ & $.75^{* *}$ & $.38^{* *}$ & $.32^{* *}$ & $.49^{* *}$ & $.44^{* *}$ & $-.27^{* *}$ & $.37^{* *}$ & $.52^{* *}$ & $.90^{* *}$ & 1 & & & & & & \\
\hline 12 & PEB & $.23^{* *}$ & $.25^{* *}$ & $.58^{* *}$ & $.45^{* *}$ & $.20^{* *}$ & $.26^{* *}$ & $-.17^{*}$ & $.18^{*}$ & .14 & $.37^{* *}$ & $.40^{* *}$ & 1 & & & & & \\
\hline 13 & PENA & $.16^{*}$ & $.18^{*}$ & $.44^{* *}$ & $.62^{* *}$ & $.36^{* *}$ & $.21^{* *}$ & $-.23^{* *}$ & .08 & $.17^{*}$ & $.19^{* *}$ & $.24^{* *}$ & $.37^{* *}$ & 1 & & & & \\
\hline 14 & Connectedness to nature & $.49^{* *}$ & $.56^{* *}$ & $.32^{* *}$ & $.29^{* *}$ & $.55^{* *}$ & $.41^{* *}$ & $-.26^{* *}$ & $.32^{* *}$ & $.43^{* *}$ & $.65^{* *}$ & $.69^{* *}$ & $.26^{* *}$ & $.27^{* *}$ & 1 & & & \\
\hline 15 & Positive Affect & $.48^{* *}$ & $.42^{* *}$ & $.17^{*}$ & $.20^{* *}$ & $.19^{* *}$ & $.67^{* *}$ & $-.53^{* *}$ & $.65^{* *}$ & $.61^{* *}$ & $.60^{* *}$ & $.52^{* *}$ & $.24^{* *}$ & $.18^{*}$ & $.49^{* *}$ & 1 & & \\
\hline 16 & Negative Affect & $-.49^{* *}$ & $-.22^{* *}$ & $-.16^{*}$ & -.13 & -.04 & $-.49^{* *}$ & $.64^{* *}$ & $-.51^{* *}$ & $-.46^{* *}$ & $-.56^{* *}$ & $-.32^{* *}$ & $-.19^{* *}$ & $-.15^{*}$ & $-.32^{* *}$ & $-.64^{* *}$ & 1 & \\
\hline 17 & Satisfaction with day & $.51^{* *}$ & $.43^{* *}$ & $.22^{* *}$ & $.19^{* *}$ & $.19^{* *}$ & $.58^{* *}$ & $-.50^{* *}$ & $.65^{* *}$ & $.66^{* *}$ & $.64^{* *}$ & $.55^{* *}$ & $.28^{* *}$ & .13 & $.46^{* *}$ & $.85^{* *}$ & $-.66^{* *}$ & 1 \\
\hline 18 & Meaning presence & $.51^{* *}$ & $.44^{* *}$ & $.21^{* *}$ & $.21^{* *}$ & $.24^{* *}$ & $.58^{* *}$ & $-.45^{* *}$ & $.62^{* *}$ & $.71^{* *}$ & $.62^{* *}$ & $.54^{* *}$ & $.23^{* *}$ & $.17^{*}$ & $.52^{* *}$ & $.81^{* *}$ & $-.59^{* *}$ & $.91^{* *}$ \\
\hline
\end{tabular}


Table 3

Results from Multilevel Regression Models with Daily Mindfulness as Predictor and Time-Lagged Variables

\begin{tabular}{|c|c|c|c|c|c|c|c|c|c|c|c|c|}
\hline \multirow[t]{2}{*}{ Dependent variables } & \multicolumn{4}{|c|}{$\begin{array}{c}\text { Same-day mindfulness } \\
\text { as predictor }\end{array}$} & \multicolumn{4}{|c|}{$\begin{array}{l}\text { Lagged mindfulness } \\
\text { as predictor }\end{array}$} & \multicolumn{4}{|c|}{$\begin{array}{l}\text { Mindfulness as dependent } \\
\text { variable (inversed model) }\end{array}$} \\
\hline & $b$ & $S E b$ & $\beta$ & $p$ & $b$ & $S E b$ & $\beta$ & $\mathrm{p}$ & $b$ & $S E b$ & $\beta$ & $p$ \\
\hline Connectedness to Nature & 0.74 & 0.05 & .48 & $<.001$ & 0.11 & 0.06 & .07 & .064 & -0.03 & 0.02 & -.04 & .141 \\
\hline PENA & 0.27 & 0.05 & .15 & $<.001$ & -0.08 & 0.06 & -.04 & .157 & -0.01 & 0.02 & -.01 & .744 \\
\hline PEB & -1.32 & 1.31 & -.04 & .314 & 4.06 & 4.06 & .13 & $<.001$ & $<0.00$ & 0.00 & .03 & .170 \\
\hline \multicolumn{13}{|l|}{ Well-being measures } \\
\hline Positive Affect & 0.86 & 0.05 & .63 & $<.001$ & 0.09 & 0.06 & -.07 & .126 & -0.01 & 0.02 & -.01 & .681 \\
\hline Negative Affect & -0.74 & 0.05 & -.55 & $<.001$ & -0.12 & 0.06 & -.09 & .027 & 0.03 & 0.02 & .04 & .182 \\
\hline Satisfaction with day & 1.33 & 0.10 & .61 & $<.001$ & 0.23 & 0.10 & .10 & .018 & -0.03 & 0.01 & -.07 & .015 \\
\hline Meaning Presence & 1.01 & 0.09 & .45 & $<.001$ & 0.17 & 0.09 & .08 & .064 & 0.03 & 0.03 & .08 & .462 \\
\hline
\end{tabular}

Note. Sample size same-day models: $N=181$, days $=1172-1183$. Sample size lagged models: $N=181$, days $=986-999$. PEB $=$ Pro-environmental behavior. PENA = Personal ecological norm activation. All Models were controlled for age, nature contact and COVID-19-treat. The full models can be found in the supplementary materials (Tables D, E, F). 


\section{Table 4}

Results from Multilevel Regression Models with Daily Observing as Predictor and Time-Lagged Variables

\begin{tabular}{|c|c|c|c|c|c|c|c|c|c|c|c|c|}
\hline \multirow[t]{2}{*}{ Dependent variables } & \multicolumn{4}{|c|}{$\begin{array}{c}\text { Same-day observing } \\
\text { as predictor }\end{array}$} & \multicolumn{4}{|c|}{$\begin{array}{l}\text { Lagged observing } \\
\text { as predictor }\end{array}$} & \multicolumn{4}{|c|}{$\begin{array}{l}\text { Observing as dependent } \\
\text { variable (inversed model) }\end{array}$} \\
\hline & $b$ & $S E b$ & $\beta$ & $p$ & $b$ & $S E b$ & $\beta$ & $\mathrm{p}$ & $b$ & $S E b$ & $\beta$ & $p$ \\
\hline Connectedness to Nature & 0.58 & 0.04 & .47 & $<.001$ & 0.13 & 0.05 & .11 & .004 & -0.02 & 0.03 & .02 & .457 \\
\hline PENA & 0.22 & 0.04 & .15 & $<.001$ & -0.01 & 0.04 & -.00 & .894 & 0.01 & 0.02 & .01 & .673 \\
\hline PEB & -0.39 & 1.01 & -.01 & .701 & 2.61 & 0.89 & .11 & .004 & $<0.00$ & 0.00 & .09 & $<.001$ \\
\hline \multicolumn{13}{|l|}{ Well-being measures } \\
\hline Positive Affect & 0.34 & 0.04 & .31 & $<.001$ & 0.09 & 0.04 & .08 & .039 & 0.01 & 0.02 & .02 & .767 \\
\hline Negative Affect & -0.21 & 0.04 & -.19 & $<.001$ & -0.04 & 0.04 & -.04 & .270 & 0.02 & 0.02 & .02 & .381 \\
\hline Satisfaction with day & 0.53 & 0.07 & .30 & $<.001$ & 0.15 & 0.07 & .09 & .028 & $<0.00$ & 0.01 & -.00 & .849 \\
\hline Meaning Presence & 0.48 & 0.07 & .27 & $<.001$ & 0.15 & 0.07 & .08 & .023 & 0.02 & 0.02 & -.04 & .123 \\
\hline
\end{tabular}

Note. Sample size same-day models: $N=181$, days $=1172-1183$. Sample size lagged models: $N=181$, days $=989-1002 \cdot$ PEB $=$ Pro-environmental behavior, PENA = Personal ecological norm activation. All Models were controlled for age, nature contact and COVID-19-treat. The full models can be found in the supplementary materials (Tables G, H, I). 


\subsection{Daily Mindfulness as Predictor of Subsequent Day's Connectedness to Nature, PENA, PEB and}

\section{Well-being}

Time-lagged observing predicted connectedness to nature positively ( $\beta_{\text {Lagged observing }}=.11, p$ $=.004)$, while the inversed model including connectedness to nature as a time-lagged predictor was not significant ( $\beta_{\text {Lagged CNS }}=.02, p=.457$ ). This points out to an effect of observing on next day's feelings of nature connectedness. Similar, time-lagged mindfulness showed a small relationship to PEB ( $\beta_{\text {Lagged }}$ mindfuness $=.13, \mathrm{p}<.001)$. In contrast, lagged PEB was not significantly related to the subsequent day's mindfulness ( $\beta_{\text {Lagged PEB }}=.03, p=.170$ ). This indicates an effect of mindfulness on next day's PEB. Also, time-lagged observing showed a small relationship to PEB ( $\left.\beta_{\text {Lagged mindfulness }}=.11, p=.004\right)$, but inversely, time-lagged PEB predicted mindfulness significantly as well $\left(\beta_{\text {Lagged PEB }}=.09, p<.001\right)$, indicating no systematical connection between observing and next day's PEB.

With regard to well-being, time-lagged mindfulness showed a small negative effect on negative affect ( $\left.\beta_{\text {Lagged mindfulness }}=-.09, p=.027\right)$, while inversely, lagged negative affect had no significant effect on mindfulness ( $\beta_{\text {Lagged negative affect }}=.04, p=.182$ ), pointing out that high mindfulness leads to less negative emotions also on the subsequent day. This was also the case for time-lagged observing, which showed small connections to positive affect ( $\left.\beta_{\text {Lagged observing }}=.08, p=.039\right)$, to satisfaction with day $\left(\beta_{\text {Lagged observing }}=.09, p=.028\right)$ and meaning presence $\left(\beta_{\text {Lagged observing }}=.08, p=\right.$ .023). The inversed models showed no significant relationships to observing, indicating that high observing is related to higher positive affect, satisfaction with day and meaning presence on the next day. The main results are summarized in Tables 3 and 4 . The complete models can be found in the supplementary materials (Tables $\mathrm{E}, \mathrm{F}, \mathrm{H}$ and $\mathrm{I}$ ). 


\subsection{Mind-body Practice as a Moderator}

To test the proposed interaction effect between daily mindfulness and MBP (practice-naïve / regular practitioners), interaction variables were added to the models as a predictor. There were no significant interaction effects, neither for mindfulness and MBP, nor for observing and MBP. MBP as a main effect showed a significant relationship with connectedness to nature in the models with mindfulness $\left(\beta_{\mathrm{MBP}}=.17, \mathrm{p}=.002\right)$ and observing $\left(\beta_{\mathrm{MBP}}=.14, \mathrm{p}=.002\right)$, indicating that regular practitioners reported higher feelings of connectedness to nature in daily life. Similar, MBP was positively related to pro-environmental behavior in the models with mindfulness ( $\beta_{\mathrm{MBP}}=.34, p=.029$ ) and observing ( $\left.\beta_{M B P}=.34, p=.028\right)$. This points out that regular practitioners act more frequently proenvironmentally in daily life. The interaction effects and the main effects of mindfulness, observing and MBP are summarized in Tables 5 and 6 . The complete models including the test statistics of the controls as well as the exact sample size can be found in the online supplementary materials (Tables J and $\mathrm{K})$. 


\section{Table 5}

Results from Multilevel Regression with Inclusion of Interaction between Mindfulness and Mind-body Practice

$b \quad S E b \quad \beta \quad p$

\begin{tabular}{|c|c|c|c|c|}
\hline DV: PEB & & & & \\
\hline Mindfulness & -1.04 & 2.64 & .05 & .694 \\
\hline MBP & 8.34 & 3.75 & .34 & .029 \\
\hline Mindfulness x MBP & 0.61 & 3.64 & .08 & .866 \\
\hline \multicolumn{5}{|l|}{ DV: PENA } \\
\hline Mindfulness & 0.37 & 0.10 & .26 & $<.001$ \\
\hline MBP & -0.01 & 0.05 & .06 & .832 \\
\hline Mindfulness $x$ MBP & -0.10 & 0.14 & -.04 & .476 \\
\hline \multicolumn{5}{|l|}{ DV: Connectedness to Nature } \\
\hline Mindfulness & 0.80 & 0.10 & .51 & $<.001$ \\
\hline MBP & 0.49 & 0.16 & .17 & .002 \\
\hline Mindfulness x MBP & -0.1 & 0.14 & .00 & .470 \\
\hline \multicolumn{5}{|l|}{ DV: Positive Affect } \\
\hline Mindfulness & 0.77 & 0.10 & .59 & $<.001$ \\
\hline MBP & 0.06 & 0.17 & -.29 & .741 \\
\hline Mindfulness $x$ MBP & 0.12 & 0.13 & .06 & .363 \\
\hline \multicolumn{5}{|l|}{ DV: Negative Affect } \\
\hline Mindfulness & -0.65 & 0.10 & -.46 & $<.001$ \\
\hline MBP & 0.06 & 0.15 & .32 & .684 \\
\hline Mindfulness x MBP & 0.05 & 0.14 & -.02 & .735 \\
\hline \multicolumn{5}{|l|}{ DV: Satisfaction with day } \\
\hline Mindfulness & 1.24 & 0.16 & .54 & $<.001$ \\
\hline MBP & 0.32 & 0.23 & -.09 & .159 \\
\hline Mindfulness x MBP & -0.05 & 0.22 & .00 & .808 \\
\hline \multicolumn{5}{|l|}{ DV: Meaning Presence } \\
\hline Mindfulness & 0.76 & 0.16 & .41 & $<.001$ \\
\hline MBP & 0.38 & 0.23 & .01 & .100 \\
\hline Mindfulness x MBP & 0.15 & 0.23 & .02 & .496 \\
\hline
\end{tabular}

Note. $N=95$ (45 non-practitioners, 52 regular practitioners), days $=622-628$.

$\mathrm{PEB}=$ Pro-environmental behavior. $\mathrm{PENA}=$ Personal ecological norm activation . $\mathrm{MBP}=$ Mind-body practice ( $0=$ non-practitioners, $1=$ regular practitioners $)$. The full models can be found in the supplementary materials (Table J). 


\section{Table 6}

Results from Multilevel Regression with Inclusion of Interaction between Observing and Mind-body Practice

$b \quad$ SEB $\quad \beta \quad \mathrm{p}$

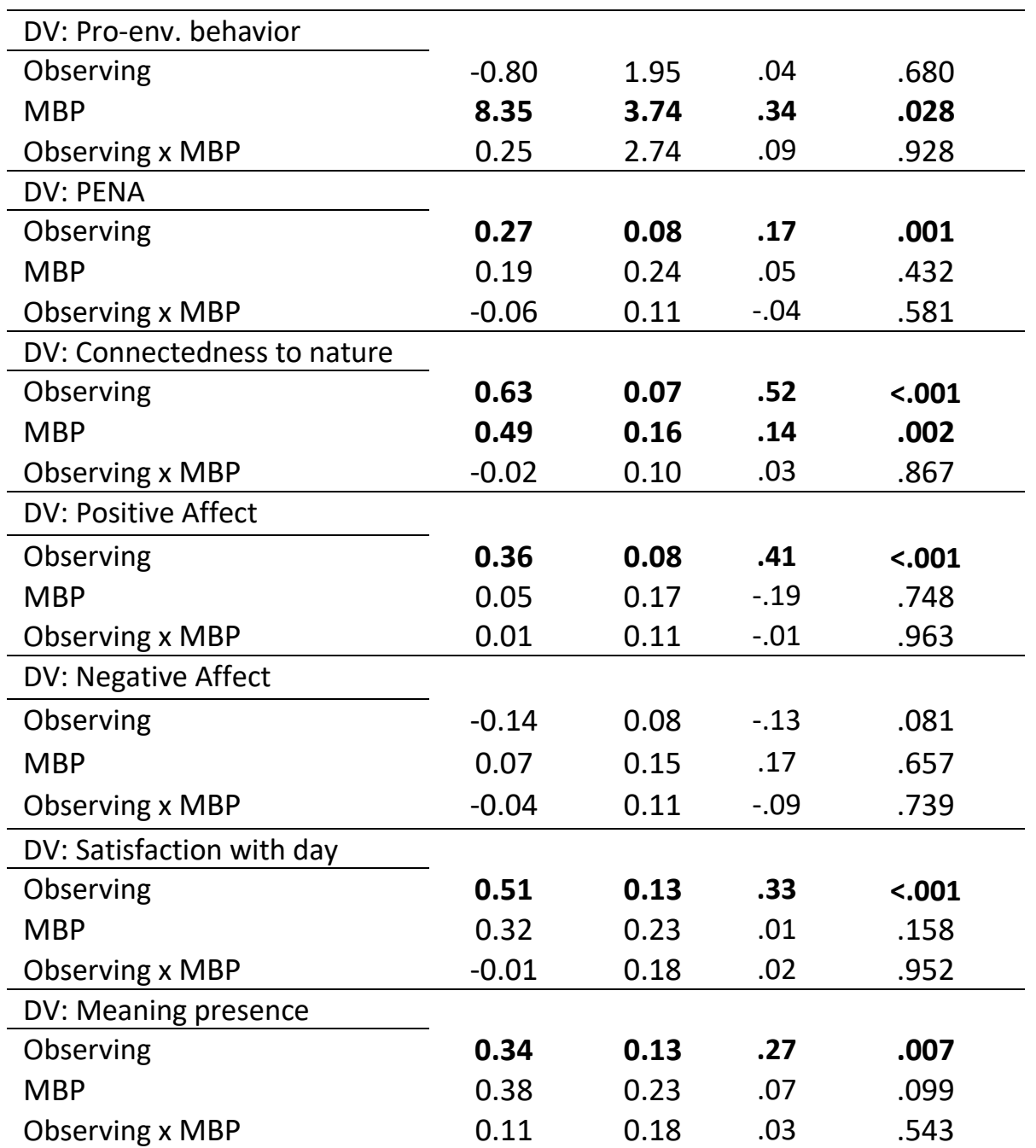

Note. $N=95$ (45 non-practitioners, 52 regular practitioners), days $=625-631$.

$\mathrm{PEB}=$ Pro-environmental behavior. $\mathrm{PENA}=$ Personal ecological norm activation. $\mathrm{MBP}=$ Mind-body practice $(0=$ non-practitioners, $1=$ regular practitioners $)$.

The full models can be found in the supplementary materials (Table $\mathrm{K}$ ). 


\subsection{Path Models with Mindfulness, Connectedness to Nature, Personal Ecological Norm and PEB}

Based on the previous regression analyses and theoretical assumptions, we tested path models to investigate the relationships between mindfulness, connectedness to nature, personal norm and PEB. Using the daily data, a multilevel path model was conducted to test relationships between the variables and indirect effects of mindfulness. The standardized beta weights for the paths are depicted in Figure 2. On the same-day within-person level (see lower part of Figure 2), mindfulness was positively related to connectedness to nature $\left(a_{1 \mathrm{w}}: b=0.20, \beta_{\text {mindfulness }}=.48, p<.001\right)$ and PENA ( $\left.\mathrm{a}_{2 \mathrm{w}}: b=.15, \beta_{\text {mindfuness }}=.09, \mathrm{p}=.011\right)$, indicating that in a day mindfulness covariates positively with feelings of nature connectedness and feelings of obligation to act pro-environmentally. Moreover, connectedness to nature predicted same-day PENA positively $\left(\mathrm{d}_{21 \mathrm{w}}: b=.20, \beta_{\mathrm{CNS}}=.22\right.$, $p<.001)$, indicating that in a day high feelings of nature connectedness, individuals feel at the same time obligated to behave pro-environmentally. PENA in turn showed a small relationship to PEB $\left(b_{2 w}\right.$ : $\left.b=2.60, \beta_{\mathrm{PENA}}=.10, \mathrm{p}=.004\right)$, which points out that the feeling of obligation toward proenvironmental action is also connected to pro-environmental behavior choices. There was no significant total effect of mindfulness on PEB before controlling for the mediators ( $c_{w}: b=-2.20$, $\left.\beta_{\text {mindfulness }}=-.06, p=.122\right)$ and also no direct effect after controlling for the mediators $\left(c^{\prime}{ }_{w}: b=-2.60\right.$, $\left.\beta_{\text {mindfulness }}=-.07, p=.068\right)$. The indirect effect of mindfulness on PEB occurred to be significant with a weak, but non-substantial effect ( $\left.a_{1 w} * d_{21 w} * b_{2 w}: b=.40, \beta_{\text {mindfuness }}=.01,95 \% \mathrm{Cl}[.10, .71]\right)$.

On the between-person level (see upper part of Figure 2), mindfulness was strongly related to connectedness to nature $\left(\mathrm{a}_{1 \mathrm{~b}}: b=.92, \beta_{\text {mindfulness-b }}=.67, \mathrm{p}<.001\right)$, indicating the tendency that mindful individuals felt at the same time high nature connectedness. The relation between connectedness to nature and PENA ( $\left.\mathrm{d}_{21 \mathrm{~b}}: b=.35, \beta_{\mathrm{CNS}-\mathrm{b}}=.26, \mathrm{p}=.016\right)$, furthermore points out that on average the stronger individuals felt connected to nature, the higher they felt obligated to act pro- 
environmentally. Additionally, PENA was related positively to PEB ( $\left.b_{2 \mathrm{~b}}: b=4.83, \beta_{\text {PENA-b}}=.35, p<.001\right)$, which indicates that individuals who reported a high obligation to act pro-environmentally, also reported to perform more pro-environmental behaviors during the study participation period. Overall on the between-person level, mindfulness showed a medium strong total effect on PEB before controlling for the mediators $\left(c_{b}: b=.12 .28, \beta_{\text {mindfulness- } b}=.46,95 \% \mathrm{Cl}[6.95,17.61]\right)$. Also, after controlling for the mediators the effect remained medium strong $\left(c^{\prime}{ }_{b}: b=10.71, \beta_{\text {mindfulness- } b}=.40,95 \%\right.$ $\mathrm{Cl}[5.59,15.82])$. A weak significant indirect effect on PEB $\left(\mathrm{a}_{1 \mathrm{~b}}{ }^{*} \mathrm{~d}_{21 \mathrm{~b}} * \mathrm{~b}_{2 \mathrm{~b}}: \mathrm{b}=.75, \beta_{\text {mindfulness-b }}=.06,95 \%\right.$ $\mathrm{Cl}[.10,3.05])$, indicated a partial mediation of the relationship between mindfulness and PEB through connectedness to nature and personal ecological norm.

The same path model using the pre-questionnaire data yielded significant weights for all proposed paths that were overall comparable to the between-person model using the daily data. The total effect of mindfulness on PEB was small ( $\left.c_{p q}: b=.15, \beta_{\text {mindfulness }-\mathrm{pq}}=.20,95 \% \mathrm{Cl}[.06 ., .24]\right)$ and when controlling for the mediators ( $\left.c^{\prime}{ }_{p q}: b=.08, \beta_{\text {mindfulness-pq }}=.11,95 \% \mathrm{Cl}[-.01,0.16]\right)$, mindfulness showed no significant relationship to PEB, which indicates a full mediation through connectedness to nature and PENA. There was a small indirect effect of mindfulness on PEB $\left(a_{1 p q} * d_{21 p q}{ }^{*} b_{2 p q}: b=.07, \beta\right.$ mindfulness-pq $=.09,95 \% \mathrm{Cl}[.03, .11])$. The model including the standardized beta weights is summarized in Figure 3. 


\section{Figure 2}

Multilevel Path Model with Daily Mindfulness, Connectedness to Nature, Personal Ecological Norm Activation and Pro-Environmental Behavior (Daily Diary Data)

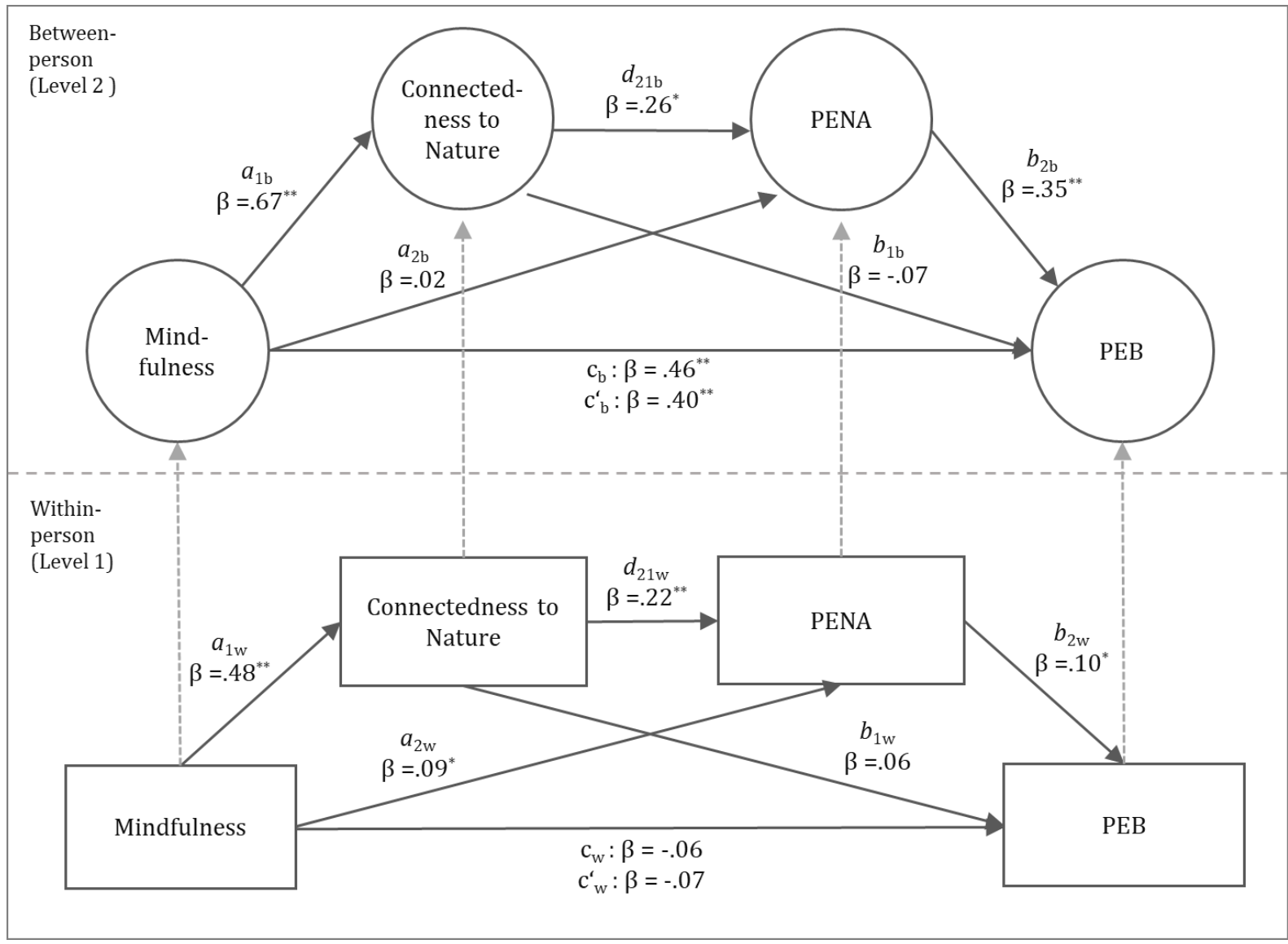

Note. Standardized beta coefficients. Days $=1186$ (level1, $N=183$ (level 2). Fit Indices: CFI = .1.00, TLI $=.1 .00 . \mathrm{RMSEA}=.00,90 \% \mathrm{Cl}[.00, .00], \mathrm{SRMR}=.00$. 


\section{Figure 3}

Path Model with Daily Mindfulness, Connectedness to Nature, Personal Ecological Norm and ProEnvironmental Behavior (Pre-Questionnaire Data)

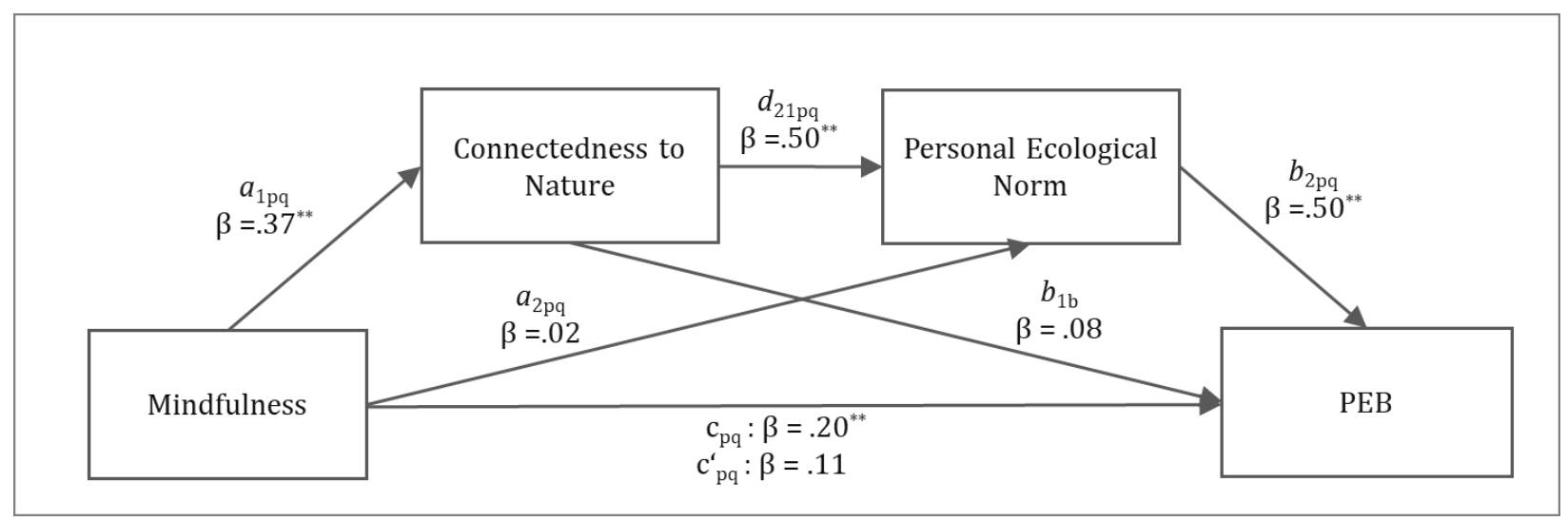

Note. Standardized beta coefficients. $N=183$. Fit Indices: $\mathrm{CFI}=.1 .00, \mathrm{TLI}=.1 .00 . \mathrm{RMSEA}=.00,90 \% \mathrm{Cl}$ $[.00, .00]$, SRMR $=.00$. 


\section{Discussion}

The goal of the present study was to gain insights about the role of mindfulness in relation to connectedness to nature, PENA, PEB and well-being on an within-person level. The results show significant connections of mindfulness and observing to same-day connectedness to nature and PENA, suggesting that individuals who are mindful in a day, feel stronger connected to nature and a higher moral obligation to behave pro-environmentally friendly. Beyond this, the mindfulness facet of observing predicted in addition subsequent day's connectedness to nature, which confirms the specifically relevant role of observing. One particular interesting result is that mindfulness was significantly related to next day's PEB, pointing out to a time-lagged effect of mindfulness on PEB. The path model furthermore confirms connections between the central variables of the present study in a daily within-person level. Thereby, a path from mindfulness to PEB over connectedness to nature and PENA was found, but however no direct nor substantial indirect effect of mindfulness on PEB occurred.

In sum, the results show across the different analyses that mindfulness may be an important everyday predictor of behaviorally close variables (connectedness to nature and PENA), but however does not directly covariate with PEB on a same-day level. The effect of mindfulness on PEB on the next day rather suggest an effect of mindfulness PEB that is not immediate, but may point out to psychological processes that evolve in this time period.

Additional analyses showed, that mindfulness as well as observing were significantly related to all of the same-day well-being measures, and is in addition significantly but weakly related to subsequent day's well-being. This indicates that mindfulness in daily life is not only related to predictors of PEB, but is also accompanied by individual well-being. Furthermore, including only regular mind-body practitioners and naïve study participants showed that MBP is positively related to connectedness to 
nature and PEB, indicating that regular practitioners feel stronger nature connectedness and act more frequently pro-environmentally in their daily life.

\subsection{Mindfulness is Related to Same-day Connectedness to Nature, Observing to Subsequent Day's Connectedness to Nature}

One central result of the present study is the comparatively high connection between daily mindfulness and same-day connectedness to nature. This result is consistent with previous studies that identified connections between self-reported mindfulness and connectedness to nature (Hanley et al., 2020; Howell et al., 2011; Ray et al., 2020). This relationship indicates, that mindfulness does relate to feelings of nature connectedness also on a short-term daily time frame and on a withinperson level, and also when simultaneously controlling for same-day contact to nature. Responsible for this connection may be a higher awareness toward natural elements through mindfulness and possibly initiated by this awareness - a sense of interrelatedness of oneself with the natural world (Howell et al., 2011). Furthermore, this connection was not only present with mindfulness as a predictor, but also with the facet of observing, which additionally showed beyond the same-day a small effect on next day's connectedness to nature. As this effect was not significantly in the reversed direction (connectedness to nature predicts subsequent day's mindfulness), this result may point out to a causal relationship as mindfulness is the temporally preceding variable (West and Hepworth, 1991). The specific relevance of the observing facet in relation to connectedness to nature has been already identified in previous studies (Barbaro and Pickett, 2016), pointing out that the conscious awareness of internal and external stimuli may play an important role in this connection. However, it should be noted that this result is not highly significant, the effect is very small and therefore needs further replication. Especially because sometimes a reciprocal relationship between mindfulness and connectedness to nature is discussed, assuming that also connectedness to nature may increase 
mindfulness as well (Schutte and Malouff, 2018).

Furthermore, connectedness to nature showed a significant, small connection to personal ecological norm activation in the within-person path model. This points out that individuals who feel connected to nature, also feel a personal obligation to act pro-environmentally and this also in the short time frame within one day. Previous studies already found that individuals who report high nature connectedness are more likely to protect nature through their behavior (Mackay and Schmitt, 2019). Feelings of nature connectedness may be an explanation of this connection as it may be an every-day reminder that enhance the salience of individual of responsibility to protect the environment through one's actions.

\subsection{The Role of Personal Ecological Norm Activation}

The results confirm that daily mindfulness is accompanied by same-day feelings of personal obligation to act in a more pro-environmentally friendly manner. This direct connection may point out to the general mechanism of mindfulness to clarify and active personal goals and values (Shapiro et al., 2006). However, the regression weights are small across the different analyses, indicating a comparatively weak predictive value of mindfulness with regard to the explanation of the personal ecological norm on a within-person level.

Similarly, the same-day within person path models furthermore confirmed a weak relationship between personal ecological norm activation and pro-environmental behavior. This is generally, in line with the NAM (Schwartz, 1977) or the VBN-theory of environmentalism (Stern et al., 1999), in which a personal norm is the central predictor of behavior. However, also in this case, the connection is surprisingly very weak, pointing out to a rather behavior-distal factor when looking on a short-term within-day level. Still, as the general personal ecological norm is empirically and theoretically one of the most important predictors of PEB, even small weights on PENA on a daily level can be considered 
as not irrelevant. They still may have concrete effects on behavioral outcomes over time (Funder and Ozer, 2019). More specifically, increasing PENA by one scale point is associated with an increase in carrying out $2.2 \%$ more PEB of the options on average each day. As the measure of PEB consists of concrete ecologically relevant behaviors, a small increase indicates at least slightly different behavior decisions, which have an ecological impact on the long-term.

\subsection{Effect of Mindfulness on Next Day's Pro-Environmental Behavior}

Mindfulness was not connected to PEB on a same-day level, but however predicted subsequent day's PEB. This points generally out, that mindfulness is not connected to PEB within the short time frame of a day, but may have a time-delayed effect. Furthermore, as this connection was not found in the reversed order (PEB predicts subsequent day's mindfulness), the result is a first indication of a causal relationship. Considered together with the missing same-day connection of mindfulness and PEB, this may point out, that the mechanisms of mindfulness to enhance PEB are indirect and evolve slower than within one day. This result is contrary to the idea, which is sometimes suggested, that a mindful awareness is directly connected to ecological behavioral decisions, for example during shopping (Bahl et al., 2016; Fischer et al., 2017). Several reasons for this relationship can be discussed. One reason for the time lag might that intrapsycholocial processes are initiated during this time delay between mindfulness and PEB. As already mentioned, the relationship between mindfulness and PEB is often assumed to be mediated by different psychological qualities, such as an activation of values, which may need time to become salient. Interesting is further though that the time-delayed relationship to PEB could unexpectedly not be confirmed with the mindfulness facet of observing as predictor, although it is sometimes discussed as the key aspect of mindfulness (Lilja et al., 2013). This indicates, that the inclusion of the other mindfulness facets, acting with awareness, non-judging, non-reactivity and describing contributes to the time-delayed connection between mindfulness and PEB. However, based on the present study no conclusions about the specific psychological processes that are 
involved can be derived.

Another reason for the effect of mindfulness on next day's PEB could be the methodological focus on the daily level. The evaluation of one's mindfulness may have already led to an increase and a bias in daily mindfulness. In the same way, the daily monitoring of the specific behaviors may have led to the behavioral options being more salient and therefore more likely to be chosen on the next day. Although in those analyses, the models were statistically controlled for the effect of previous day PEB on PEB, the daily monitoring may have influenced the results.

\subsection{Mind-body Practice is related to Daily Connectedness to Nature and Pro-environmental Behavior}

Regular MBP was related positively to daily PEB and connectedness to nature, indicating that regular practitioners are feeling stronger connected to nature and act more often proenvironmentally compared to practice-naïve individuals. Interesting is furthermore the positive relationship of MBP to PEB, that occurred in the analyses, suggesting that MBP may have an independent contribution in explaining PEB. This is consistent with a study by Thiermann et al. (2020) that found a lower diet-related ecological impact as well as higher connectedness to nature in advanced mindfulness meditators. The study also identified an "integrated motivation" to be higher in meditators, which can be described as the degree to which the intention to live environmentally friendly has become an integral part of life. In this context, Thiermann and Sheate (2020a) furthermore suggest mindfulness meditation, along with nature exposure, to be an experiential strategy that activates a pathway towards pro-environmental behavior mainly through connectedness to nature, empathy and compassion. Furthermore, a study by Loy and Reese (2019) showed that MBP is related to PEB, mediated by global identity. The authors suggest one reason to be the universalistic goal of "a sense of connectedness with all humans" that is often pursued in MBP. In 
combination with the present findings it would be interesting if there a general sense of interrelatedness, which includes nature and humanity as well might be present in mind-body practitioners. Contemplative practices can be a way to cultivate prosocial qualities, cognitive insight as well as purpose and meaning (Dahl and Davidson, 2019). Also, there is evidence that reasons for long-term practitioners to continue their practice are not only personal development, but also to open up and care for others (Sedlmeier and Theumer, 2020). Studies further show that regular meditators are in general more meaning-orientated compared to non-meditators (Richter and Hunecke, 2021). However, because MBP was included in the present study only as a dichothom group variable, the question as to whether the effect is directly attributable to the daily practice dosage (Goldberg et al., 2020) or a specific type of practice remains open. The investigation of MBP and its relation to daily varying psychological predictors of PEB could be interesting for future studies. Nevertheless, only (quasi-)experimental study designs with specific mindfulness-based interventions could give insights into causal connections between mindfulness practice and those variables.

The results show that the relations between mindfulness and connectedness to nature, PENA, PEB and well-being do not differ in regular practitioners in comparison to practice-naïve individuals. Therefore, the original hypothesis that MBP moderates these relationships could not be confirmed. One reason for this might be that practitioners show in comparison to naïve individuals already higher mindfulness, and therefore the addition of MBP does not explain additional variance in the dependent variables. In conclusion there is no evidence that in regular mind-body practitioners the proposed same-day relationships between mindfulness, connectedness to nature, PENA, PEB and well-being are particularly strong. 


\subsection{Within- and Between-person Pathways from Mindfulness to PEB}

The path analyses overall confirmed the suggested relationships in both, the daily and the pre-questionnaire data. Those analyses provide a comprehensive overview of the results of different measurement methods (daily diary vs. cross-sectional) and analysis levels (within- vs. betweenperson). While previous studies on mindfulness and PEB predominantly analyzed cross-sectional data, the present study is the first that also provides results from a daily diary study design. Using this approach, a daily within-person pathway from mindfulness to PEB over connectedness to nature and PENA was confirmed. Thereby, the path overall confirms a theoretically well-grounded intrapersonal process from mindfulness to PEB, that has been partly tested previously on a general between-person level (Howell et al., 2011; Hunecke and Richter, 2019; Schutte and Malouff, 2018). The path confirms that individual mindfulness in a day is accompanied by feelings of nature connectedness, which may activate a stronger feeling of personal obligation to act pro-environmentally. This personal ecological norm is in turn related to PEB.

The between-person path model using the daily data confirms overall the proposed pathway and shows additionally a significant indirect effect of mindfulness on PEB, which is partially mediated by connectedness to nature and PENA. In addition, the path model was examined with the data from the pre-questionnaire. In addition to this model, the path model was also tested with the data from the pre-questionnaire, which is similar overall but shows some differences in detail in the regression weights. Reasons for the differences between both between-person pathways may be the different measurement of the variables in the pre-questionnaire compared to the daily measurement. In the cross-sectional pre-questionnaire the psychological constructs were mostly conceptionalized as dispositions or traits respectively and they related to a broader time span compared to the diary data. For example, PEB was answered with reference to the last four weeks. However, the strength of the 
found connection between mindfulness and PEB is very similar to previous studies (Geiger et al., 2019), assuring a certain comparability with other studies.

\subsection{Mindfulness Predicts Same-day and Subsequent Day's Well-being}

Daily mindfulness was strongly connected with same-day hedonic (positive and negative affect, satisfaction with day) as well as eudaimonic aspects of well-being (presence of meaning), which confirms the relevance of mindfulness for well-being on a same-day and within-person level. The results indicate that individuals who report high mindfulness also feel more satisfied with their day, experience stronger positive and less negative emotions, and experience their day as more meaningful. This confirms previous diary studies that found a positive relation between mindfulness and affective well-being (Brockman et al., 2017; Mahlo and Windsor, 2021). Furthermore, the results give first indications that not only at a between-person level mindfulness is connected to satisfaction with life and meaning in life (Allan et al., 2015; Mesmer-Magnus et al., 2017), but also on a more finegrained intrapersonal level in daily life.

In general, the connection of observing to the well-being measures were considerably smaller in comparison to the overall mindfulness scale. One reason might be that well-being enhancing meta mechanisms of mindfulness such as decentering or reperceiving (Shapiro et al., 2006) are conceptually close to the facets of nonreactivity or nonjudging and not specifically to observing.

Furthermore, mindfulness as well as the facet of observing showed some effects on the subsequent day's well-being, indicating an effect of mindfulness on well-being that lasts beyond the same day. With regard to affective well-being, the results confirm the study by Snippe et al. (2015). Although all of these effects were very weak, they may point to a causal connection, as the connections were not found in the reversed direction (e.g. positive affect did not predict subsequent day's mindfulness). 


\subsection{Limitations and Future Studies}

Some limitations of the present study should be noted. The data is based on a convenience sample and is not representative for the German population. A great majority of the participants were female and most of them were highly educated. This strongly limits the transferability and generalizability of the present results to other populations. Furthermore, the survey period was only over a maximum of one week. Although we excluded some participants for example because they reported extraordinary events, a longer period of time would additionally enhance the reliability of the results. Furthermore, the data were collected during the second COVID-19-wave in Germany and accompanying lockdown measures. We integrated in most of the analyses a range of variables to control the changed circumstances as well as feelings of threat through the pandemic. Still, it is questionable as to whether the present results can be transferred to post-pandemic times. The pandemic and the containment measures not only influenced individual well-being (Zacher and Rudolph, 2021) but also lead to a lower consumption of material goods and to a shift in leisure activities (Hüppauff et al., 2021), that may have an effect on individual PEB.

Daily mindfulness appeared to be relatively stable across the measurement points, indicating that a great proportion of the variability in mindfulness can be explained by between-person differences. A higher variability in mindfulness may be reached through the assessment of situational state mindfulness or when the study is accompanied by a structured mindfulness-based intervention including mindfulness practice. The combination of momentary measurement of momentary mindfulness state through experience sampling in combination with regular mindfulness practice could be interesting for future studies to investigate potential mindfulness processes, such as the activation of the personal ecological norm or behavior intentions, that relate to PEB-decisions more closely. As consequences of momentary mindfulness for PEB-decisions may be initiated by 
psychological processes that need time to evolve, the investigation over longer time frames would be needed.

To measure daily PEB, we developed a novel instrument which is based on specific ecological relevant behaviors that have a proven ecological impact. Non-regular PEB decisions such as choosing an energy provider, the purchase of electronic devices or clothes were not part of the daily instrument, as they did not fit into the daily logic. For this reason, the investigated PEB is only an indicator for daily behaviors and conclusions about the total individual PEB and the ecological impact might not be valid. Furthermore, all behaviors were included unweighted in the score, although the behaviors differed strongly in their ecological impact. Future studies could calculate a weighted score using $\mathrm{CO}_{2}$-equivalents to estimate the influence of mindfulness and the other variables not only on PEB frequency, but also on the ecological impact of the PEB score. The inclusion of both as dependent variables could be interesting, as individuals are often unaware of the ecological impact of their lifestyle (Bleys et al., 2018). Also, in the PEB score, all of the behavioral areas were aggregated. The disaggregated measurement and analysis of those areas might have revealed more differentiated results for example for the domains of nutrition and clothing that were found to be correlated with mindfulness (Geiger et al., 2019). In general, the daily assessment of PEB is relatively seldom used in pro-environmental research. The present study showed that PEB-decisions in every-day life do vary between days and that those variations may be partly explained by psychological factors. An advantage of this approach is furthermore the temporal proximity of the daily measurement, which enables a behavior-close fine-grained analysis of psychological predictors. Also, because action theories that aim to explain PEB, assume often intrapersonal psychological process to be involved, the investigation of within-person relationships seems promising also in other contexts than mindfulness. 
In general, the present study has put a focus on connectedness to nature and personal ecological norm activation as potential mediating variables. However, since the number of studies to date on the topic of mindfulness and PEB in general is limited, it is necessary to extensively test other suggested pathways (for an overview see Thiermann and Sheate, 2020b). Also, to be able to assess the potential of mindfulness, the differentiated definition and examination of mindfulness as a trait and mindfulness as a practice in order to gain well-grounded insights is needed (van Dam et al., 2018). Also, through the multidimensionality of mindfulness, it is a major challenge to identify the aspects of mindfulness responsible for the found correlations between mindfulness and PEB. In order to draw conclusions regarding mindfulness mechanisms, it may be also necessary to investigate metamechanisms of mindfulness, such as decentering (Bernstein et al., 2015; Shapiro et al., 2006), in relation to PEB and predictors of PEB. Furthermore, many authors suggest to well-being to be a central motivating factor when pointing to the potential of mindfulness for pro-environmental behavior (e.g. Ericson et al., 2014). However, the role of different well-being types in this connection has not been investigated very much. As confirmed in the present study, mindfulness shows a stable connection to well-being. At the same time, it is suggested that PEB can be connected to higher levels of well-being (Venhoeven et al., 2020), which may especially the case when pro-environmental action is perceived as meaningful. It may be possible that mindfulness does not only contribute to a motivation to act pro-environmentally, but also supports positive experiences when doing so. Those dynamics are interesting for future research, as some authors already theoretically suggested upward spirals that can be initiated by mindfulness (Garland et al., 2015) and may be related to high wellbeing and a more sustainable lifestyle (Hunecke, 2020). 


\subsection{Conclusion}

The present study investigated mindfulness and its relationship to PEB as well as the connectedness to nature and personal norm on a daily within-person level using a daily diary study. The results confirmed same-day connections of mindfulness to connectedness to nature and personal ecological norm activation, pointing out to the relevance of mindfulness for behaviorally-close factors in a short time frame. There was no evidence for a connection between mindfulness and PEB on a same-day level, but however, mindfulness had an effect on next day's PEB. This indicates that mindfulness may have a time-delayed effect on PEB, rather than an immediate effect on behavior decisions. Additionally, the study suggests an independent contribution of MBP in explaining daily connectedness to nature and PEB which is interesting for future investigations. Furthermore, the strong relationship between mindfulness and well-being indicates that mindfulness comprises a path to a sustainable lifestyle that can go along with the maintenance of personal well-being.

By measuring multiple time points it was possible to test and compare the proposed relationships not only between-person, but also within-person. Through this approach, the study contributed to a better understanding at the individual intrapersonal level of the relationship between mindfulness and PEB. In sum, the results show that the differentiated measurement of the constructs on a daily level allow a better understanding of pathways from mindfulness to proenvironmental behavior. 
Acknowledgements: The Authors thank Stefan Richter for his support in programming the individual feedback statistics algorithm for the study participants.

Data Availability Statement: Supplementary materials, data and R scripts are available at OSF: https://osf.io/pw7zs/?view only=c313667dc41f401593a29ef1fd4ae460

Funding: This research did not receive any specific grant from funding agencies in the public, commercial, or not-for-profit sectors. 


\section{References}

Allan, B.A., Bott, E.M., Suh, H., 2015. Connecting Mindfulness and Meaning in Life: Exploring the Role of Authenticity. Mindfulness 6, 996-1003. https://doi.org/10.1007/s12671-014-0341-z.

Arslan, R.C., Walther, M.P., Tata, C.S., 2020. formr: a study framework allowing for automated feedback generation and complex longitudinal experience-sampling studies using R. Beh. Res. Methods 52, 376-387. https://doi.org/10.3758/s13428-019-01236-y.

Baer, R.A., Smith, G.T., Lykins, E., Button, D., Krietemeyer, J., Sauer, S., Walsh, E., Duggan, D., Williams, J.M.G., 2008. Construct validity of the Five Facet Mindfulness Questionnaire in meditating and nonmeditating samples. Assessment 15, 329-342.

https://doi.org/10.1177/1073191107313003.

Bahl, S., Milne, G.R., Ross, S.M., Mick, D.G., Grier, S.A., Chugani, S.K., Chan, S.S., Gould, S., Cho, Y.-N., Dorsey, J.D., Schindler, R.M., Murdock, M.R., Boesen-Mariani, S., 2016. Mindfulness: Its Transformative Potential for Consumer, Societal, and Environmental Well-Being. J. Public. Policy 35, 198-210. https://doi.org/10.1509/ippm.15.139.

Bamberg, S., Möser, G., 2007. Twenty years after Hines, Hungerford, and Tomera: A new metaanalysis of psycho-social determinants of pro-environmental behaviour. J. Environ. Psychol. 27, 14-25. https://doi.org/10.1016/i.jenvp.2006.12.002.

Barbaro, N., Pickett, S.M., 2016. Mindfully green: Examining the effect of connectedness to nature on the relationship between mindfulness and engagement in pro-environmental behavior. Pers. Indiv. Differ. 93, 137-142. https://doi.org/10.1016/j.paid.2015.05.026.

Bates, D., Mächler, M., Bolker, B., Walker, S., 2015. Fitting linear mixed-effects models using Ime4. J. Stat. Soft. 67. https://doi.org/10.18637/jss.v067.i01.

Bergomi, C., Tschacher, W., Kupper, Z., 2014. Konstruktion und erste Validierung eines Fragebogens zur umfassenden Erfassung von Achtsamkeit [Construction and initial validation of a 
questionnaire for the comprehensive assessment of mindfulness]. Diagnostica 60, 111-125. https://doi.org/10.1026/0012-1924/a000109.

Bernstein, A., Hadash, Y., Lichtash, Y., Tanay, G., Shepherd, K., Fresco, D.M., 2015. Decentering and related constructs: a critical review and metacognitive processes model. Perspect. Psychol. Sci. 10, 599-617. https://doi.org/10.1177/1745691615594577.

Bishop, S.R., Lau, M., Shapiro, S., Carlson, L., Anderson, N., Carmody, J., Segal, Z., Abbey, S., Speca, M, Velting, D., Devins, G., 2004. Mindfulness: a proposed operational definition. Clin. Psychol. Sci. Pr. 11, 230-241. https://doi.org/10.1093/clipsy/bph077.

Bissing-Olson, M.J., lyer, A., Fielding, K.S., Zacher, H., 2013. Relationships between daily affect and pro-environmental behavior at work: the moderating role of pro-environmental attitude. J. Organiz. Behav. 34, 156-175. https://doi.org/10.1002/job.1788.

Bleys, B., Defloor, B., van Ootegem, L., Verhofstadt, E., 2018. The environmental impact of individual behavior: Self-assessment versus the ecological footprint. Environ. Behav. 50, 187-212. https://doi.org/10.1177/0013916517693046.

Bratt, C., Stern, P.C., Matthies, E., Nenseth, V., 2015. Home, car use, and vacation: the structure of environmentally significant individual behavior. Environ. Behav. 47, 436-473. https://doi.org/10.1177/0013916514525038.

Brockman, R., Ciarrochi, J., Parker, P., Kashdan, T., 2017. Emotion regulation strategies in daily life: Mindfulness, cognitive reappraisal and emotion suppression. Cogn. Behav. Therapy 46, 91-113. https://doi.org/10.1080/16506073.2016.1218926.

Brown, K.W., Kasser, T., 2005. Are psychological and ecological well-being compatible? The role of values, mindfulness, and lifestyle. Soc. Indic. Res. 74, 349-368. https://doi.org/10.1007/s11205004-8207-8. 
Brügger, A., Kaiser, F.G., Roczen, N., 2011. One for all? Connectedness to nature, inclusion of nature, environmental identity, and implicit association with nature. Eur. Psychol. 16, 324-333. https://doi.org/10.1027/1016-9040/a000032.

Capaldi, C.A., Dopko, R.L., Zelenski, J.M., 2014. The relationship between nature connectedness and happiness: a meta-analysis. Front. Psychol. 5, 976. https://doi.org/10.3389/fpsyg.2014.00976. Chu, P.-Y., Chiu, J.-F., 2003. Factors influencing household waste recycling behavior: Test of an integrated model. J. Appl. Social Pyschol. 33, 604-626. https://doi.org/10.1111/j.15591816.2003.tb01915.x.

Cleary, A., Fielding, K.S., Murray, Z., Roiko, A., 2020. Predictors of nature connection among urban residents: Assessing the role of childhood and Adult Nature Experiences. Environ. Behav. 52, 579610. https://doi.org/10.1177/0013916518811431.

Curran, P.J., Bauer, D.J., 2011. The disaggregation of within-person and between-person effects in longitudinal models of change. Annu. Rev. Psychol. 62, 583-619.

https://doi.org/10.1146/annurev.psych.093008.100356.

Dahl, C.J., Davidson, R.J., 2019. Mindfulness and the contemplative life: Pathways to connection, insight, and purpose. Curr. Opin. Psychol. 28, 60-64.

https://doi.org/10.1016/j.copsyc.2018.11.007.

Diener, E., Emmons, R.A., Larsen, R.J., Griffin, S., 1985. The Satisfaction With Life Scale. J. Per. Assess. 49, 71-75. https://doi.org/10.1207/s15327752jpa4901 13.

Diener, E., Wirtz, D., Biswas-Diener, R., Tov, W., Kim-Prieto, C., Choi, D., Oishi, S., 2009. New measures of well-being, in: Diener, E. (Ed.), Assessing Well-Being: The collected works of Ed Diener. Springer Netherlands, Dordrecht, pp. 247-266.

Eberth, J., Sedlmeier, P., 2012. The effects of mindfulness meditation: a meta-analysis. Mindfulness 3, 174-189. https://doi.org/10.1007/s12671-012-0101-x. 
Eisenlohr-Moul, T.A., Peters, J.R., Pond, R.S., DeWall, C.N., 2016. Both trait and state mindfulness predict lower aggressiveness via anger rumination: a multilevel mediation analysis. Mindfulness 7, 713-726. https://doi.org/10.1007/s12671-016-0508-x.

Ericson, T., Kjønstad, B.G., Barstad, A., 2014. Mindfulness and sustainability. Ecol. Econ. 104, 73-79. https://doi.org/10.1016/i.ecolecon.2014.04.007.

Fischer, D., Stanszus, L., Geiger, S., Grossman, P., Schrader, U., 2017. Mindfulness and sustainable consumption: A systematic literature review of research approaches and findings. J. Clean. Prod. 162, 544-558. https://doi.org/10.1016/i.jclepro.2017.06.007.

Friese, M., Hofmann, W., 2016. State mindfulness, self-regulation, and emotional experience in everyday life. Motiv. Sci. 2, 1-14. https://doi.org/10.1037/mot0000027.

Funder, D.C., Ozer, D.J., 2019. Evaluating Effect Size in Psychological Research: Sense and Nonsense. Adva. Methods Pract. Psychol. Sci. 2, 156-168. https://doi.org/10.1177/2515245919847202.

Garland, E.L., Farb, N.A., Goldin, P., Fredrickson, B.L., 2015. Mindfulness Broadens Awareness and Builds Eudaimonic Meaning: A Process Model of Mindful Positive Emotion Regulation. Psychol. Inq. 26, 293-314. https://doi.org/10.1080/1047840X.2015.1064294.

Geiger, S., Fischer, D., Schrader, U., 2018. Measuring what matters in sustainable consumption: An integrative framework for the selection of relevant behaviors. Sust. Dev. 26, 18-33. https://doi.org/10.1002/sd.1688.

Geiger, S., Fischer, D., Schrader, U., Grossman, P., 2020. Meditating for the planet: Effects of a mindfulness-based intervention on sustainable consumption behaviors. Environ. Behav. 52, 10121042. https://doi.org/10.1177/0013916519880897.

Geiger, S., Grossman, P., Schrader, U., 2019. Mindfulness and sustainability: Correlation or causation? Curr. Opin. Psychol. 28, 23-27. https://doi.org/10.1016/i.copsyc.2018.09.010. 
Geiger, S., Otto, S., Schrader, U., 2017. Mindfully green and healthy: an indirect path from mindfulness to ecological behavior. Front. Psychol. 8, 2306. https://doi.org/10.3389/fpsyg.2017.02306.

Geldhof, G.J., Preacher, K.J., Zyphur, M.J., 2014. Reliability estimation in a multilevel confirmatory factor analysis framework. Psychol. Methods 19, 72-91. https://doi.org/10.1037/a0032138. Glaesmer, H., Grande, G., Braehler, E., Roth, M., 2011. The German version of the Satisfaction With Life Scale (SWLS). Eur. J. Psychol. Assess. 27, 127-132. https://doi.org/10.1027/1015$\underline{5759 / a 000058}$.

Goldberg, S.B., Hanley, A.W., Baldwin, S.A., Bernstein, A., Garland, E.L., 2020. Does mindfulness practice promote psychological functioning or is it the other way around? A daily diary study. Psychotherapy. https://doi.org/10.1037/pst0000286.

Goldberg, S.B., Tucker, R.P., Greene, P.A., Davidson, R.J., Wampold, B.E., Kearney, D.J., Simpson, T.L., 2018. Mindfulness-based interventions for psychiatric disorders: a systematic review and metaanalysis. Clin. Psychol. Rev. 59, 52-60. https://doi.org/10.1016/j.cpr.2017.10.011.

Gotink, R.A., Hermans, K.S.F.M., Geschwind, N., Nooij, R. de, Groot, W.T. de, Speckens, A.E.M., 2016. Mindfulness and mood stimulate each other in an upward spiral: a mindful walking intervention using experience sampling. Mindfulness 7, 1114-1122. https://doi.org/10.1007/s12671-016-0550$\underline{8}$.

Grossman, P., Niemann, L., Schmidt, S., Walach, H., 2004. Mindfulness-based stress reduction and health benefits. J. Psychosom. Res. 57, 35-43. https://doi.org/10.1016/S0022-3999(03)00573-7. Hamaker, E.L., Grasman, R.P.P.P., 2014. To center or not to center? Investigating inertia with a multilevel autoregressive model. Front. Psychol. 5, 1492.

https://doi.org/10.3389/fpsyg.2014.01492. 
Hanley, A.W., Bettmann, J.E., Kendrick, C.E., Deringer, A., Norton, C.L., 2020. Dispositional Mindfulness Is Associated with Greater Nature Connectedness and Self-Reported Ecological Behavior. Ecopsychology 12, 54-63. https://doi.org/10.1089/eco.2019.0017.

Hilgert, T., Behren, S. von, Eisenmann, C., Vortisch, P., 2018. Are activity patterns stable or variable? Analysis of three-year panel data. Transp. Res. Record 2672, 46-56.

https://doi.org/10.1177/0361198118773557.

Howell, A.J., Dopko, R.L., Passmore, H.-A., Buro, K., 2011. Nature connectedness: Associations with well-being and mindfulness. Pers. Indiv. Differ. 51, 166-171.

\section{https://doi.org/10.1016/j.paid.2011.03.037.}

Howell, A.J., Passmore, H.-A., Buro, K., 2013. Meaning in nature: Meaning in life as a mediator of the relationship between nature connectedness and well-being. J. Happiness Stud. 14, 1681-1696. https://doi.org/10.1007/s10902-012-9403-x.

Hu, L., Bentler, P.M., 1999. Cutoff criteria for fit indexes in covariance structure analysis: Conventional criteria versus new alternatives. Struct. Equ. Modeling 6, 1-55.

https://doi.org/10.1080/10705519909540118.

Hunecke, M., 2018. Psychology of sustainability, in: Parodi, O., Tamm, K. (Eds.), Personal sustainability: Exploring the far side of sustainable development. Routledge Taylor \& Francis Group; EBSCO Industries, London, New York, Ipswich, Massachusetts, pp. 33-50.

Hunecke, M., 2020. Psychische Ressourcen für nachhaltige Lebensstile. Eine Erweiterung der theoretischen Perspektive der Umweltpsychologie zur Förderung einer sozial-ökologischen Transformation [Psychological resources for sustainable lifestyles. An extension of the theoretical perspective of environmental psychology to promote a social-ecological transformation]. Umweltpsychologie 24, 34-60. 
Hunecke, M., Richter, N., 2019. Mindfulness, construction of meaning, and sustainable food consumption. Mindfulness 10, 446-458. https://doi.org/10.1007/s12671-018-0986-0.

Hüppauff, T.L., Richter, N., Hunecke, M., 2021. Heavy crisis, new Perspectives? Investigating the role of consumption, time wealth and meaning construction during countrywide Covid-19 lockdown in Germany. https://doi.org/10.31234/osf.io/e5684.

Huta, V., Waterman, A.S., 2014. Eudaimonia and Its Distinction from Hedonia: Developing a Classification and Terminology for Understanding Conceptual and Operational Definitions. J. Happiness Stud. 15, 1425-1456. https://doi.org/10.1007/s10902-013-9485-0.

Kabat-Zinn, J., 1990. Full catastrophe living: Using the wisdom of your body and mind to face stress, pain, and illness. Bantam Books, New York, 650 pp.

Kaiser, F.G., 1998. A general measure of ecological behavior. J. Appl. Social. Pyschol. 28, 395-422. https://doi.org/10.1111/i.1559-1816.1998.tb01712.x.

Kasser, T., 2017. Living both well and sustainably: a review of the literature, with some reflections on future research, interventions and policy. Philos. T. Roy. Soc. A 375. https://doi.org/10.1098/rsta.2016.0369.

Kiken, L.G., Garland, E.L., Bluth, K., Palsson, O.S., Gaylord, S.A., 2015. From a state to a trait: Trajectories of state mindfulness in meditation during intervention predict changes in trait mindfulness. Pers. Indiv. Differ. 81, 41-46. https://doi.org/10.1016/j.paid.2014.12.044.

Kuznetsova, A., Brockhoff, P.B., Christensen, R.H.B., 2017. ImerTest package: Tests in linear mixed effects models. J. Stat. Soft. 82. https://doi.org/10.18637/jss.v082.i13.

Lange, F., Dewitte, S., 2019. Measuring pro-environmental behavior: Review and recommendations. J. Environ. Psychol. 63, 92-100. https://doi.org/10.1016/j.jenvp.2019.04.009. 
Lilja, J.L., Lundh, L.-G., Josefsson, T., Falkenström, F., 2013. Observing as an essential facet of mindfulness: a comparison of FFMQ patterns in meditating and non-meditating individuals. Mindfulness 4, 203-212. https://doi.org/10.1007/s12671-012-0111-8.

Lorah, J., 2018. Effect size measures for multilevel models: definition, interpretation, and TIMSS example. Large-scale Assess. Educ. 6. https://doi.org/10.1186/s40536-018-0061-2.

Loy, L.S., Reese, G., 2019. Hype and hope? Mind-body practice predicts pro-environmental engagement through global identity. J. Environ. Psychol. 66, 101340. https://doi.org/10.1016/i.jenvp.2019.101340.

Maas, C.J.M., Hox, J.J., 2005. Sufficient sample sizes for multilevel modeling. Methodology 1, 86-92. https://doi.org/10.1027/1614-2241.1.3.86.

Mackay, C.M., Schmitt, M.T., 2019. Do people who feel connected to nature do more to protect it? A meta-analysis. J. Environ. Psychol. 65, 101323. https://doi.org/10.1016/i.jenvp.2019.101323.

Mahlo, L., Windsor, T.D., 2021. State mindfulness and affective well-being in the daily lives of middleaged and older adults. Psychol. Aging. https://doi.org/10.1037/pag0000596.

Maleetipwan-Mattsson, P., Laike, T., Johansson, M., 2013. Self-report diary: a method to measure use of office lighting. LEUKOS 9, 291-306. https://doi.org/10.1582/LEUKOS.2013.09.04.004.

Markle, G.L., 2013. Pro-environmental behavior: Does it matter how it's measured? Development and validation of the Pro-Environmental Behavior Scale (PEBS). Hum. Ecol. 41, 905-914. https://doi.org/10.1007/s10745-013-9614-8.

Martin, C., Czellar, S., 2017. Where do biospheric values come from? A connectedness to nature perspective. J. Environ. Psychol. 52, 56-68. https://doi.org/10.1016/i.jenvp.2017.04.009.

Mayer, S., Frantz, C.M., 2004. The connectedness to nature scale: A measure of individuals' feeling in community with nature. J. Environ. Psychol. 24, 503-515.

https://doi.org/10.1016/i.jenvp.2004.10.001. 
Mayer, S., Frantz, C.M., Bruehlman-Senecal, E., Dolliver, K., 2009. Why Is Nature Beneficial? The role of connectedness to nature. J. Environ. Psychol. 41, 607-643.

https://doi.org/10.1177/0013916508319745.

Mesmer-Magnus, J., Manapragada, A., Viswesvaran, C., Allen, J.W., 2017. Trait mindfulness at work: A meta-analysis of the personal and professional correlates of trait mindfulness. Hum. Perform. 30, 79-98. https://doi.org/10.1080/08959285.2017.1307842.

Michalak, J., Zarbock, G., Drews, M., Otto, D., Mertens, D., Ströhle, G., Schwinger, M., Dahme, B., Heidenreich, T., 2016. Erfassung von Achtsamkeit mit der deutschen Version des Five Facet Mindfulness Questionnaires (FFMQ-D) [Assessment of mindfulness with the German version of the Five Facet Mindfulness Questionnaire (FFMQ-D)]. Z. Gesundheitspsychologie 24, 1-12. https://doi.org/10.1026/0943-8149/a000149.

Nezlek, J.B., 2012. Diary methods for personality and social psychology. Sage, Los Angeles, 158 pp. Nezlek, J.B., Newman, D.B., Thrash, T.M., 2017. A daily diary study of relationships between feelings of gratitude and well-being. J. Posit. Psychol. 12, 323-332.

https://doi.org/10.1080/17439760.2016.1198923.

Nisbet, E.K., Zelenski, J.M., Murphy, S.A., 2011. Happiness is in our nature: Exploring nature relatedness as a contributor to subjective well-being. J. Happiness Stud. 12, 303-322. https://doi.org/10.1007/s10902-010-9197-7.

Ohly, S., Sonnentag, S., Niessen, C., Zapf, D., 2010. Diary studies in organizational research: an introduction and some practical recommendations. J. Pers. Psychol. 9, 79-93. https://doi.org/10.1027/1866-5888/a000009.

Panno, A., Giacomantonio, M., Carrus, G., Maricchiolo, F., Pirchio, S., Mannetti, L., 2018. Mindfulness, pro-environmental behavior, and belief in climate change: The mediating role of social dominance. Environ. Behav. 50, 864-888. https://doi.org/10.1177/0013916517718887. 
R Core Team, 2020. R: A language and environment for statistical computing. R Foundation for Statistical Computing, Vienna, Austria. https://www.R-project.org.

Ray, T.N., Franz, S.A., Jarrett, N.L., Pickett, S.M., 2020. Nature enhanced meditation: Effects on mindfulness, connectedness to nature, and pro-environmental behavior. Environ. Behav., 001391652095245. https://doi.org/10.1177/0013916520952452.

Richter, N., Hunecke, M., 2020. Facets of mindfulness in stages of behavior change toward organic food consumption. Mindfulness 11, 1354-1369. https://doi.org/10.1007/s12671-020-01351-4.

Richter, N., Hunecke, M., 2021. The mindful hedonist? Relationships between well-being orientations, mindfulness and well-being experiences. J. Happiness Stud. https://doi.org/10.1007/s10902-021$\underline{00358-5 .}$

Rosseel, Y., 2012. lavaan : An R package for structural equation modeling. J. Stat. Soft. 48. https://doi.org/10.18637/iss.v048.i02.

Rudkin, E., Medvedev, O.N., Siegert, R.J., 2018. The Five-Facet Mindfulness Questionnaire: Why the observing subscale does not predict psychological symptoms. Mindfulness 9, 230-242. https://doi.org/10.1007/s12671-017-0766-2.

Schutte, N.S., Malouff, J.M., 2018. Mindfulness and connectedness to nature: A meta-analytic investigation. Pers. Indiv. Differ. 127, 10-14. https://doi.org/10.1016/j.paid.2018.01.034. Schwartz, S.H., 1977. Normative influences on altruism. Adv. Epx. Soc. Psychol. 10, 221-279. https://doi.org/10.1016/S0065-2601(08)60358-5.

Sedlmeier, P., Theumer, J., 2020. Why do people begin to meditate and why do they continue? Mindfulness 11, 1527-1545. https://doi.org/10.1007/s12671-020-01367-w.

Shapiro, S.L., Carlson, L.E., Astin, J.A., Freedman, B., 2006. Mechanisms of mindfulness. J. Clin. Psychol. 62, 373-386. https://doi.org/10.1002/iclp.20237. 
Snippe, E., Nyklíček, I., Schroevers, M.J., Bos, E.H., 2015. The temporal order of change in daily mindfulness and affect during mindfulness-based stress reduction. J. Couns. Psychol. 62, 106-114. https://doi.org/10.1037/cou0000057.

Sparks, P., Hinds, J., Curnock, S., Pavey, L., 2014. Connectedness and its consequences: a study of relationships with the natural environment. J. Appl. Social Pyschol. 44, 166-174. https://doi.org/10.1111/jasp.12206.

Steg, L., Vlek, C., 2009. Encouraging pro-environmental behaviour: An integrative review and research agenda. J. Environ. Psychol. 29, 309-317. https://doi.org/10.1016/i.jenvp.2008.10.004.

Steger, M.F., Frazier, P., Oishi, S., Kaler, M., 2006. The meaning in life questionnaire: Assessing the presence of and search for meaning in life. J. Couns. Psychol. 53, 80-93. https://doi.org/10.1037/0022-0167.53.1.80.

Stern, P., Dietz, T., Abel, T., Guagnano, G., Kalof, L., 1999. A value-belief-norm theory of support for social movements: The case of environmentalism. Hum. Ecol. Rev. 6, 81-97.

Thiermann, U.B., Sheate, W.R., 2020a. Motivating individuals for social transition: The 2-pathway model and experiential strategies for pro-environmental behaviour. Ecol. Econ. 174, 106668. https://doi.org/10.1016/i.ecolecon.2020.106668.

Thiermann, U.B., Sheate, W.R., 2020b. The way forward in mindfulness and sustainability: a critical review and research agenda. J. Cogn. Enhanc. https://doi.org/10.1007/s41465-020-00180-6. Thiermann, U.B., Sheate, W.R., Vercammen, A., 2020. Practice Matters: Pro-environmental motivations and diet-related impact vary with meditation experience. Front. Psychol. 11, 584353. https://doi.org/10.3389/fpsyg.2020.584353.

Thogersen, J., Olander, F., 2006. The dynamic interaction of personal norms and environment-friendly buying behavior: A panel study. J. Appl. Social Psychol. 36, 1758-1780. https://doi.org/10.1111/i.0021-9029.2006.00080.x. 
Unsworth, S., Palicki, S.-K., Lustig, J., 2016. The impact of mindful meditation in nature on self-nature interconnectedness. Mindfulness 7, 1052-1060. https://doi.org/10.1007/s12671-016-0542-8. van Dam, N.T., van Vugt, M.K., Vago, D.R., Schmalzl, L., Saron, C.D., Olendzki, A., Meissner, T., Lazar, S.W., Kerr, C.E., Gorchov, J., Fox, K.C.R., Field, B.A., Britton, W.B., Brefczynski-Lewis, J.A., Meyer, D.E., 2018. Mind the Hype: A Critical Evaluation and Prescriptive Agenda for Research on Mindfulness and Meditation. Perspect. Psychol. Sci. 13, 36-61.

https://doi.org/10.1177/1745691617709589.

Venhoeven, L.A., Bolderdijk, J.W., Steg, L., 2020. Why going green feels good. Journal of Environmental Psychology, 101492. https://doi.org/10.1016/j.jenvp.2020.101492.

Visted, E., Vøllestad, J., Nielsen, M.B., Nielsen, G.H., 2015. The Impact of Group-Based Mindfulness Training on Self-Reported Mindfulness: a Systematic Review and Meta-analysis. Mindfulness 6, 501-522. https://doi.org/10.1007/s12671-014-0283-5.

West, S.G., Hepworth, J.T., 1991. Statistical issues in the study of temporal data: daily experiences. J. Pers. 59, 609-662. https://doi.org/10.1111/j.1467-6494.1991.tb00261.x.

Zacher, H., Rudolph, C.W., 2021. Individual differences and changes in subjective wellbeing during the early stages of the COVID-19 pandemic. Am. Psychol. 76, 50-62.

https://doi.org/10.1037/amp0000702. 